\title{
Study on the Electronic Structure and Enhanced Photoelectrocatalytic Performance of RuxZn1- $\mathrm{xO} / \mathrm{Ti}$ Electrodes
}

Yanqun Shao ( $\sim$ yqshao1989@163.com )

Fuzhou University

Keke Feng

Fuzhou University

Jie Guo

Fuzhou University

Rongrong Zhang

Fuzhou University

Sijiang He

Fuzhou University

Xinli Wei

Fuzhou University

Yuting Lin

Fuzhou University

Zhanghao Ye

Fuzhou University

Kongfa Chen

Fuzhou University

\section{Research Article}

Keywords: RuxZn1-xO/Ti electrode. first-principles calculation, electric collector, photoelectric synergistic catalysis

Posted Date: January 18th, 2021

DOI: https://doi.org/10.21203/rs.3.rs-142224/v1

License: (c) (1) This work is licensed under a Creative Commons Attribution 4.0 International License.

Read Full License 


\section{Cover letter}

\section{Dear Longtu LI}

We would like to submit the enclosed manuscript entitled "Study on the electronic structure and enhanced photoelectrocatalytic performance of $\mathrm{Ru}_{\mathrm{x}} \mathrm{Zn}_{1-\mathrm{x}} \mathrm{O} / \mathrm{Ti}$ electrodes" by Yanqun Shao, Keke Feng, Jie Guo, Rongrong Zhang, Sijiang He, Xinli Wei, Yuting Lin, Zhanghao Ye, Kongfa Chen, which we wish to public in the "Journal of Advanced Ceramics".

As reported in our paper, $\mathrm{Ru}_{\mathrm{x}} \mathrm{Zn}_{1-\mathrm{x}} \mathrm{O} / \mathrm{Ti}$ electrodes with high photoelectrocatalytic (PEC) property were prepared by thermal decomposition method, and the first-principles calculation was adopted to analyze the effect of $\mathrm{Ru}$ content on the electronic structure of $\mathrm{Ru}_{\mathrm{x}} \mathrm{Zn}_{1-\mathrm{x}} \mathrm{O}$ coatings. The results indicated that when $\mathrm{Zn}^{2+}$ replaced by $\mathrm{Ru}^{4+}$ in the lattice of $\mathrm{ZnO}$, impurity energy level gradually appeared in $\mathrm{ZnO}$ band gap, which increased the number of photogenerated carriers. Besides, $\mathrm{RuO}_{2}$ nanoparticles covered on $\mathrm{ZnO}$ nanorods surface, acting as highly efficient electron transfer channels and electrocatalytic active sites, could separate photogenerated electron-hole pairs and enhance PEC performance effectively. Meanwhile, adding $\mathrm{Ru}$ ions could offset such disadvantages of $\mathrm{ZnO}$ as oversized band gap and high recombination rate of photo-generated carrier. In this study, electrodes with an $\mathrm{Ru}$ content of 9.375mol\% exhibited highest PEC efficiency, which could degrade organic substances dissolved in aqueous solution effectively $(\mathrm{RhB} 97 \%, 120 \mathrm{~min})$. and much higher than the combination of simple electrocatalysis (EC 12\%) and photocatalysis (PC 50\%), confirming the synergy of photoelectrocatalysis. Furthermore, the PEC degradation mechanism of the $\mathrm{Ru}_{\mathrm{x}} \mathrm{Zn}_{1-}$ ${ }_{\mathrm{x}} \mathrm{O} / \mathrm{Ti}$ electrodes was also tentatively presented. 
we believe that this paper will be attractive to the readers of Journal of Advanced Ceramics as the $\mathrm{Ru}_{0.09375} \mathrm{Zn}_{0.90625} \mathrm{O} / \mathrm{Ti}$ electrodes prepared in this study could degrade organic matter in industrial wastewater effectively, the effect of adding $\mathrm{Ru}$ ions on the electronic structure and PEC properties of $\mathrm{ZnO}$ was also analyzed and explained in detail, which provides a useful reference for further related research.

This paper has not been submitted to other institutions for publication, in whole or in part, and all the authors listed have approved that the manuscript is enclosed.

We have read and abided by the statement of ethical standards for manuscripts submitted to Journal of Advanced Ceramics.

Thank you so much for reading and reviewing our manuscript. looking forward to hearing from you soon.

Correspondence and phone calls about the paper should be directed to Yanqun Shao at the following address, phone and fax number, and e-mail address:

Corresponding author: Yanqun Shao (Professor)

Institute: College of Materials Science and Engineering, Fuzhou University

Address: College of Materials Science and Engineering, Fuzhou University, Xueyuan Road 2, Fuzhou, Fujian 350108, China.

Tel: $+86-18950477698 \quad$ Fax: $+86-591-22866539$

E-mail: yqshao1989@163.com 


\section{Referees}

\section{Yaobo Hu,}

College of Materials Science and Engineering, Chongqing University, Chongqing 400045, China

Tel: $+86-13436117593$

Email: yaobohu@,163.com

He is an expert on this topic.

\section{Yan Lei,}

Department of Materials Engineering, College of Power and Mechanical Engineering, Wuhan University, Wuhan, Hubei 430072 China

Tel: $+86-18607131630$

Email: yappee@126.com

She did this very well in the related field.

\section{Yong Zheng,}

College of Materials Science and Engineering, Nanjing University of Aeronautics and Astronautics, Najing, Jiangsu 210026, China.

Tel: +86-13913017769

Email: zheng_only@,263.net

He may be proficient in the content that I have written. 


\section{Study on the electronic structure and enhanced photoelectrocatalytic performance of $\mathrm{Ru}_{\mathrm{x}} \mathrm{Zn}_{1-\mathrm{x}} \mathrm{O} / \mathrm{Ti}$ electrodes}

Yanqun Shao, a,b, ${ }^{\text {a }}$ Keke Feng, ${ }^{a}$ Jie Guo, ${ }^{a}$ Rongrong Zhang, ${ }^{a}$ Sijiang He, ${ }^{a}$ Xinli Wei, ${ }^{a}$ Yuting Lin, ${ }^{a}$ Zhanghao Ye, ${ }^{\text {a }}$ Kongfa Chen, ${ }^{\mathrm{a}}$

${ }^{\text {a }}$ College of Materials Science and Engineering, Fuzhou University, Fuzhou, Fujian 350108, China

${ }^{\mathrm{b}}$ College of Zhicheng, Fuzhou University, Fuzhou, Fujian 350002, China

${ }^{*}$ Corresponding authors. Tel.: +86 18950477698

E-mail address: yqshao1989@163.com (Y. Shao)

All author. E-mail addresses: yqshao1989@163.com (Y. Shao)

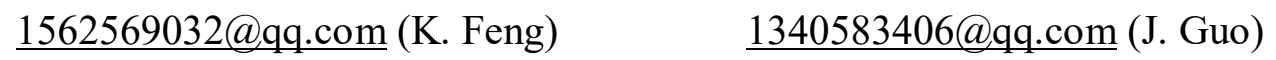

1197853866@qq.com (R. Zhang) 1059720593@qq.com (S. He)

1091427214@qq.com (X.Wei) 331513557@qq.com (Y. Lin)

578169849@qq.com (Z. Ye)～kongfa.chen@fzu.edu.cn (K. Chen) 
Abstract: Modification is one of the most important and effective methods to improve the photoelectrocatalytic (PEC) performance of $\mathrm{ZnO}$. In this paper, the $\mathrm{Ru}_{\mathrm{x}} \mathrm{Zn}_{1-\mathrm{x}} \mathrm{O} / \mathrm{Ti}$ electrodes were prepared by thermal decomposition method and the effect of $\mathrm{Ru}$ content on those electrodes' electronic structure was analyzed through the first-principles calculation. Various tests were also performed to observe the microstructures and PEC performance. The results showed that as the $\mathrm{Ru}^{4+}$ transferred into $\mathrm{ZnO}$ lattice and replaced a number of $\mathrm{Zn}^{2+}$, the conduction band of $\mathrm{ZnO}$ moved downward and the valence band went upward. The number of photogenerated electron-hole pairs increased as the impurity levels appeared in the band gap. In addition, $\mathrm{ZnO}$ nanorods exhibited a smaller grain size and a rougher surface under the effect of $\mathrm{Ru}$. Meanwhile, the $\mathrm{RuO}_{2}$ nanoparticles on the surface of $\mathrm{ZnO}$ nanorods acted as the electrontransfer channel, helping electrons transfer to the counter electrode and delaying the recombination of the electron-hole pairs. Specifically, the $\mathrm{Ru}_{\mathrm{x}} \mathrm{Zn}_{1-\mathrm{x}} \mathrm{O} / \mathrm{Ti}$ electrodes with 9.375mol\% Ru exhibited the best PEC performance with a rhodamine $\mathrm{B}(\mathrm{RhB})$ removal rate of 97\%, much higher than the combination of simple electrocatalysis (EC 12\%) and photocatalysis (PC 50\%), confirming the synergy of photoelectrocatalysis.

Keywords: $\mathrm{Ru}_{\mathrm{x}} \mathrm{Zn}_{1-\mathrm{x}} \mathrm{O} / \mathrm{Ti}$ electrode; first-principles calculation; electric collector; photoelectric synergistic catalysis 


\section{Introduction}

It was estimated that $15 \%$ of untreated organic dyes widely used in various fields have been discharged into water directly $[1,2]$. Those dyes could exist in ecosystem stably, devastate its self-degradation ability and make people suffer higher risk of intoxication, mutation and cancerization. Therefore, how to degrade organic dyes cost-effectively has become a hot topic [3-6]. One of the most widely studied method would be the semiconductor material-based PC technology. And $\mathrm{ZnO}$, an atoxic direct band gap semiconductor with a wide band gap of 3.37 $\mathrm{eV}$ and an exciton binding energy of $60 \mathrm{mV}$, has been considered as one of the most ideal materials for wastewater treatment due to its excellent PC activity, great physical and chemical stability as well as high cost efficiency $[7,8]$. It has been reported that compared with $\mathrm{TiO}_{2}$, $\mathrm{ZnO}$ exhibited higher PC efficiency in terms of the degradation of several organic contaminants in both acidic and basic medium [9, 10]. However, the high recombination rate of photogenerated electron-hole pairs and oversized band gap have significantly limited its application. Hence, how to reduce the recombination rate and enlarge the light-absorption area have received much attention $[11,12]$.

In recent years, an external bias potential placed between the anode and cathode has proven an effective method to promote the electron-hole separation rate [13-15]. Under its effect, the aforementioned recombination rate was reduced, and more electrons and holes were allowed to participate in the reaction of oxidative cracking of organic dye as the photogenerated electrons were forced to move to the counter electrode through an external circuit, while the holes remained in the valence band thanks to the external electric field. In addition, Shaoce et al. designed a dual cocatalysts for spatial separation, of which Co-Pi as the outmost hole-transfer 
layer and $\mathrm{Pt}$ as the bottom electron collector and transport layer, thereby photogenerated electrons-holes pairs were separated effectively and twice higher current density was obtained [12]. However, neither the external bias potential nor the electron collector could increase the yield of photogenerated electron-hole pairs, the light-absorption range was still relatively narrow. An efficient way to solve that problem was doping metal or non-metal elements into materials and change their electronic structure and band gap [16-19]. Ashebir et al. reported that both $\mathrm{Mn}$ - and Ag-doped $\mathrm{ZnO}$ nanoparticles showed a decreased band gap and higher PC performance relative to pure $\mathrm{ZnO}$ [20]. According to Qiu et al. who studied the effect of Ndoping on the $\mathrm{PC}$ performance of $\mathrm{ZnO}$, the forbidden band width decreased significantly and the PC activity was enhanced after the N 2p impurity energy level appeared [21]. Doping could also change the microstructure of the material $[19,22]$. Vinodkumar et al. revealed that $\mathrm{Mg}$ doped $\mathrm{ZnO}$ exhibited a significant c-axis compression and decreased grain size, its specific surface area was twice as large as that of pure $\mathrm{ZnO}[23]$.

In general, the bias potential and electron collector could reduce the recombination rate of photogenerated electron-hole pairs effectively, doping could expand the light-absorption area and change the material's microstructure. Given the fact that noble metal oxide $\mathrm{RuO}_{2}$ is an excellent electrocatalyst with high conductivity [24-26], that the atomic radius disparity between $\mathrm{Ru}^{4+}$ and $\mathrm{Zn}^{2+}$ is smaller than $7 \%$ making it possible to prepared $\mathrm{Ru}$-doped $\mathrm{ZnO}$, and that the minute difference in electronegativity between the two atoms helps form solid solutions with greater solubility [27, 28], we finally chose Ru to modify $\mathrm{ZnO}$ and analyzed its impact on the electronic structure and the PEC performance of composite-oxide electrodes. 


\section{Experimental and calculation methods}

\subsection{Preparation of $\mathrm{Ru}_{\mathrm{x}} \mathrm{Zn}_{1-\mathrm{x}} \mathrm{O} / \mathrm{Ti}$ electrodes}

Pretreatment of the Ti plates: in order to strengthen the bonding force between the substrate and the coatings, enlarge the surface area and extend the service life of the electrodes, the sandblasted $20 \times 20 \times 1.5 \mathrm{~mm}$ TA2 titanium plate was degreased, etched in $10 \mathrm{wt} \% \mathrm{H}_{2} \mathrm{SO}_{4}$ for $2 \mathrm{~h}$, then were cleaned with deionized water and preserved in absolute alcohol for further use.

Preparation of $\mathrm{Ru}_{\mathrm{x}} \mathrm{Zn}_{1-\mathrm{x}} \mathrm{O} / \mathrm{Ti}$ electrodes: the precursors $\mathrm{RuCl}_{3} \cdot \mathrm{xH}_{2} \mathrm{O}$ (containing $37 \% \mathrm{Ru}$ by mass) and $\mathrm{ZnCl}_{2}$ were used to prepare the mixed solutions with $\mathrm{Ru}$ contents of $0,3.125,6.25$, 9.375 and $12.5 \mathrm{~mol} \%$ respectively, which were stirred evenly by ultrasonic vibration. Then an appropriate amount of the mixed solution $\left(3 \mu \mathrm{cm}^{-2}\right)$ was brushed on the Ti plates, which were cured under an infrared lamp at $100{ }^{\circ} \mathrm{C}$ for $10 \mathrm{~min}$, and pre-oxidized in a muffle furnace at $500{ }^{\circ} \mathrm{C}$ for another $10 \mathrm{~min}$, followed by air cooling. After repeating those steps for six times, the samples were annealed at $500{ }^{\circ} \mathrm{C}$ for 60 min then cooled in the air, and the $\mathrm{Ru}_{\mathrm{x}} \mathrm{Zn}_{1-\mathrm{x}} \mathrm{O} / \mathrm{Ti}$ electrodes with different $\mathrm{Ru}$ contents were prepared.

\subsection{Characterization techniques}

The microstructures of the $\mathrm{Ru}_{\mathrm{x}} \mathrm{Zn}_{1-\mathrm{x}} \mathrm{O} / \mathrm{Ti}$ electrodes were observed by Scanning electron microscope (SEM, Supra 55, Carl Zeiss, Oberkochen, Germany) and Transmission electron microscope tests (TEM, TECNAI G2 F20, FEI, America). The phase structures of the coatings were studied by X-ray diffractometer test (XRD, Ultima III, Rigaku, Tokyo, Japan) with Cu K $\alpha$ radiation source and $\mathrm{Ni}$ filter, where the tube voltage and current were $36 \mathrm{kV}$ and $30 \mathrm{~mA}$, the angle range and scanning rate were $25-60^{\circ}$ and $2 \%$ min respectively. X-ray photoelectron spectroscopy (XPS) spectra were performed on the photoelectron spectroscopy system (Escalab 
250, Thermo Scientific, America), and the elemental peak fitting was performed via the Avantage software. The UV-vis diffuse reflectance spectra (DRS) were tested through the UV2600 instrument with a wavelength range of $200-800 \mathrm{~nm}$. Specific surface areas (SSA) were tested with the Micromeritics 3Flex specific surface analyzer, the samples were degassed at $200{ }^{\circ} \mathrm{C}$ for $10 \mathrm{~h}$.

\subsection{First-principles calculations}

According to the solid solution theory, both an ionic radius difference within $15 \%\left(\mathrm{Ru}^{4+}\right.$ $0.62 \AA$ vs $\mathrm{Zn}^{2+} 0.74 \AA$ ) and minute electronegativity disparity ( $\mathrm{Ru} 2.20, \mathrm{Zn} \mathrm{1.65)}$ are favorable factors, indicating the high possibility of forming $\mathrm{Ru}_{\mathrm{x}} \mathrm{Zn}_{1-\mathrm{x}} \mathrm{O}$ solid solution. Given that the ideal $\mathrm{ZnO}$ possesses a hexagonal wurtzite structure with a space group of P63/mc, a $2 \times 2 \times 2$ supercell structure model with 64 atoms was constructed, in which a small number of $\mathrm{Zn}$ and $\mathrm{Ru}$ atoms exchanged places, as shown in Fig. 1. In this study, VASP software was adopted to calculate the electronic structure of the $\mathrm{Ru}$-doped $\mathrm{ZnO}$ crystal based on the plane-wave density functional theory (DFT), where the k-point meshes of the Brillouin zone were obtained via $9 \times$ $9 \times 5$ Monkhorst-Pack grid and the plane wave cut-off energy was $520 \mathrm{eV}$.

(a)

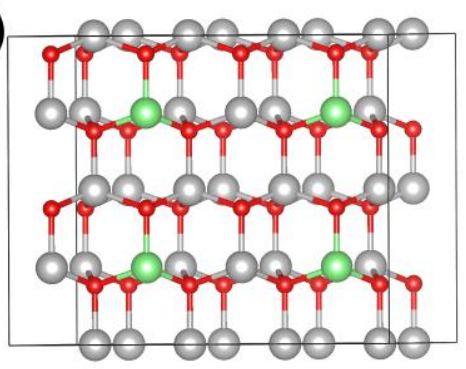

(b)

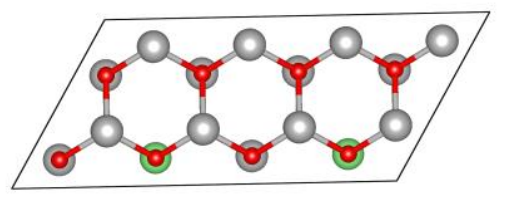

(c)

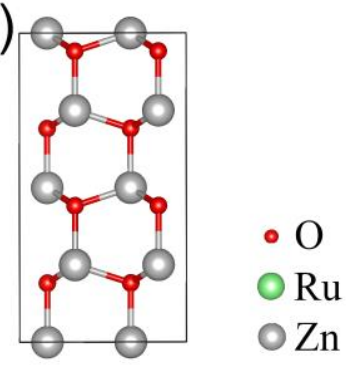

Fig. $1 \mathrm{Ru}$-doped $\mathrm{ZnO}$ with hexagonal wurtzite crystal structure (a) front view; (b) top view; (c) left view.

\subsection{Electrochemical measurements}

Electrochemical tests were performed with a three-electrode system via the Metrohm AUTOLAB Electrochemical Workstation (AUT84638, PGSTAT302N). Where the $0.1 \mathrm{M}$ 
$\mathrm{Na}_{2} \mathrm{SO}_{4}$ solution was adopted as the electrolyte, and the working, reference and counter electrodes were $\mathrm{Ru}_{\mathrm{x}} \mathrm{Zn}_{1-\mathrm{x}} \mathrm{O} / \mathrm{Ti}$ ones with different $\mathrm{Ru}$ contents, the saturated calomel electrode (SCE) and the large-area titanium plate respectively. The amplitude for electrochemical impedance spectroscopy test (EIS) was $10 \mathrm{mV}$ and the frequency range was $0.05-10^{5} \mathrm{~Hz}$. The linear sweep voltammetric (LSV) tests were performed with a potential range of 0-2.5 V and a scanning rate of $10 \mathrm{mV} \mathrm{s}^{-1}$.

\subsection{Photoelectrocatalytic degradation of RhB}

The PEC performance of the $\mathrm{Ru}_{\mathrm{x}} \mathrm{Zn}_{1-\mathrm{x}} \mathrm{O} / \mathrm{Ti}$ electrodes was evaluated by the degradation rate of $\mathrm{RhB}$. The experiment was conducted with a three-electrode configuration in a $500 \mathrm{~mL}$ cylindrical quartz beaker containing the mixed solution of $0.1 \mathrm{M} \mathrm{Na}_{2} \mathrm{SO}_{4}$ and $20 \mathrm{mg} \mathrm{L}^{-1} \mathrm{RhB}$. In which, a100 W ultraviolet mercury lamp (386 nm) was placed directly opposite the working electrode with a surface area of $4 \mathrm{~cm}^{2}$, and the light intensity $\left(15 \mathrm{~mW} \mathrm{~cm}{ }^{-2}\right)$ was monitored via a light intensity photometer (UV-M10-P/S, ORC, Japan). The solution was continuously stirred, and the potential was $2.5 \mathrm{~V}$. The removal rate of $\mathrm{RhB}$ during each degradation period was evaluated via a Cary 50 UV-vis spectrophotometer (varian) and the total organic carbon (TOC) tests were carried out through Shimadzu TOC-L ASI-L.

\section{Results and discussion}

\subsection{Microstructure morphology analysis}

As we could see from the SEM images of the $\mathrm{Ru}_{\mathrm{x}} \mathrm{Zn}_{1-\mathrm{x}} \mathrm{O} / \mathrm{Ti}$ electrodes with different $\mathrm{Ru}$ contents shown in Fig. 2., the coating surface exhibited both large and small typical hexagonal prism $\mathrm{ZnO}$ grains $[12,29]$. According to Fig. 2 (a), $\mathrm{ZnO}$ nanorods on the surface of pure $\mathrm{ZnO}$ coatings arranged orderly, possessing a relatively larger crystal grain diameter of $0.1-1 \mu \mathrm{m}$. 
However, as $\mathrm{Ru}$ content increased, $\mathrm{ZnO}$ nanorods tended to grow disorderly and the diameter gradually decreased with a few exceptions. I.e., adding Ru could reduce the grain size of $\mathrm{ZnO}$, increase the irregularity degree of coatings, and thus enlarge the specific surface area.
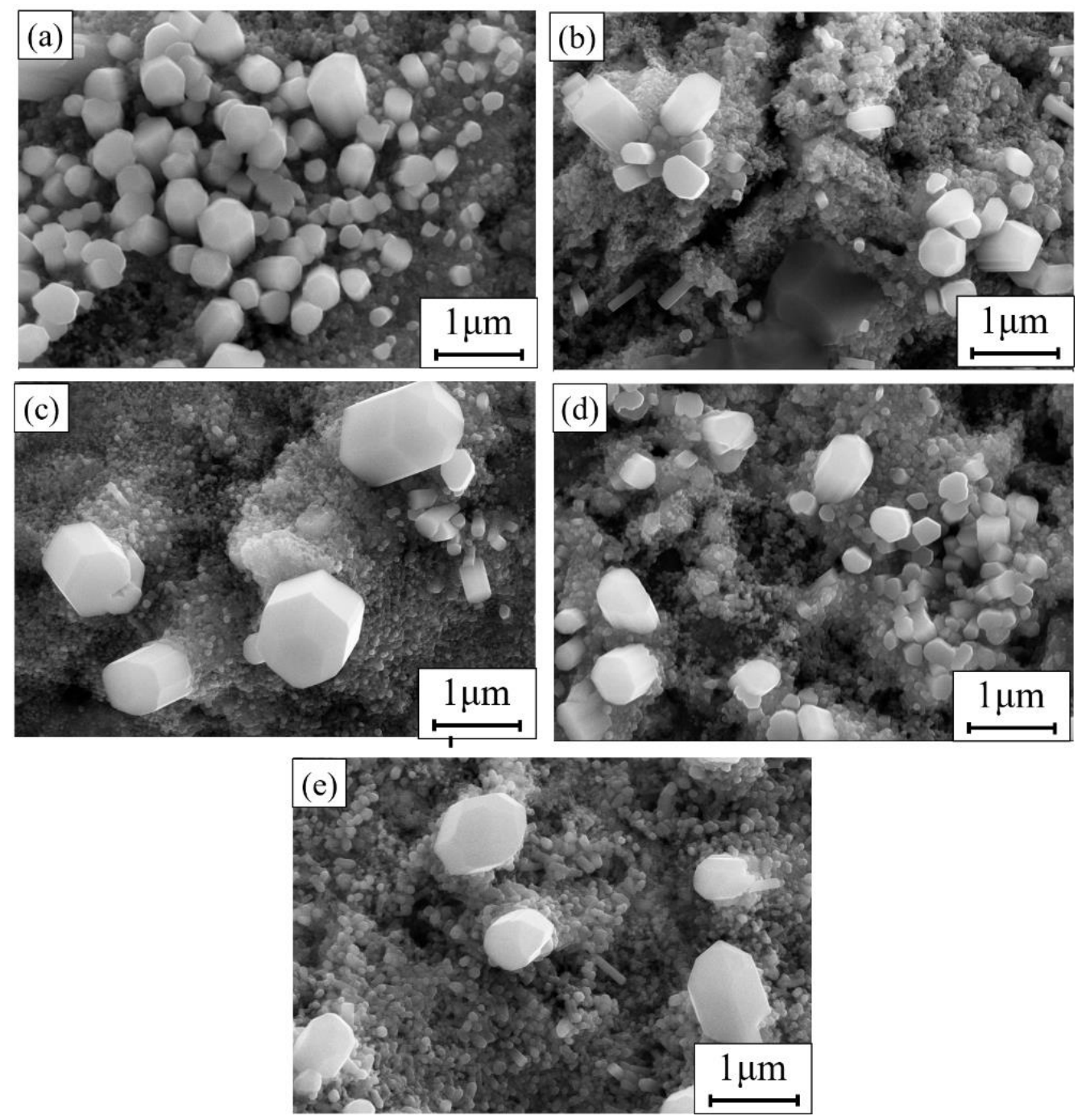

Fig. 2 SEM images of $\mathrm{Ru}_{\mathrm{x}} \mathrm{Zn}_{1-\mathrm{x}} \mathrm{O} / \mathrm{Ti}$ electrodes (a) $0 \mathrm{~mol} \%$; (b) $3.125 \mathrm{~mol} \%$; (c) $6.25 \mathrm{~mol} \%$; (d) $9.375 \mathrm{~mol} \%$; (e) $12.5 \mathrm{~mol} \%$.

Phase analysis of the $\mathrm{Ru}_{\mathrm{x}} \mathrm{Zn}_{1-\mathrm{x}} \mathrm{O} / \mathrm{Ti}$ electrodes were carried out though the XRD tests. Pure $\mathrm{ZnO}$ electrodes only exhibited the diffraction peak of hexagonal wurtzite phase $\mathrm{ZnO}$ (space group: P63/mc, JCPDS 36-1451) as displayed in Fig. 3 (a). By contrast, those $\mathrm{Ru}_{\mathrm{x}} \mathrm{Zn}_{1-\mathrm{x}} \mathrm{O} / \mathrm{Ti}$ ones showed not only the diffraction peaks of $\mathrm{ZnO}$, but the tetragonal phase of $\mathrm{RuO}_{2}$ (space group: P42/mnm, JCPDS 18-1139) and metal Ru (JCPDS 06-0663). The relatively shaper peak 
of $\mathrm{ZnO}$ indicated a higher degree of crystallization. The grain size of $\mathrm{ZnO}$ was calculated by the following Scherrer equation (applied to the (101) crystal plane) [30]:

$$
\mathrm{D}=\frac{\mathrm{k} \lambda}{\beta \cos \theta}
$$

Where $\mathrm{k}$ is the Scherrer constant $(=0.89), \lambda$ is the $\mathrm{X}$-ray wavelength of $\mathrm{Cu} \mathrm{K \alpha}(=0.154 \mathrm{~nm}), \beta$ is the full width at half maximum (FWHM) of the (101) crystal plane diffraction peak of $\mathrm{ZnO}$, and $\theta$ is the diffraction angle. According to the results shown in Table 1, the grain size of $\mathrm{ZnO}$ decreased from $33 \mathrm{~nm}$ to $26 \mathrm{~nm}$ with the increase of Ru contents, coinciding with the SEM analysis $[23,31-33]$. As shown in Fig. 3 (b), the $2 \theta$ angles of $31.769^{\circ}, 34.421^{\circ}$, and $36.252^{\circ}$ corresponded to the (100), (002), and (101) crystal planes of hexagonal wurtzite phase $\mathrm{ZnO}$ respectively. Compared with pure $\mathrm{ZnO}$, the $2 \theta$ of the three diffraction peaks of $\mathrm{Ru}$-doped ones shifted to a higher angle, the higher the $\mathrm{Ru}$ contents, the larger the deviation degree, indicating that $\mathrm{Ru}_{\mathrm{x}} \mathrm{Zn}_{1-\mathrm{x}} \mathrm{O}$ solid solution was formed after a number of $\mathrm{Zn}^{2+}$ in the $\mathrm{ZnO}$ lattice were replaced by $\mathrm{Ru}^{4+}$ with smaller radius $[32,34,35]$.
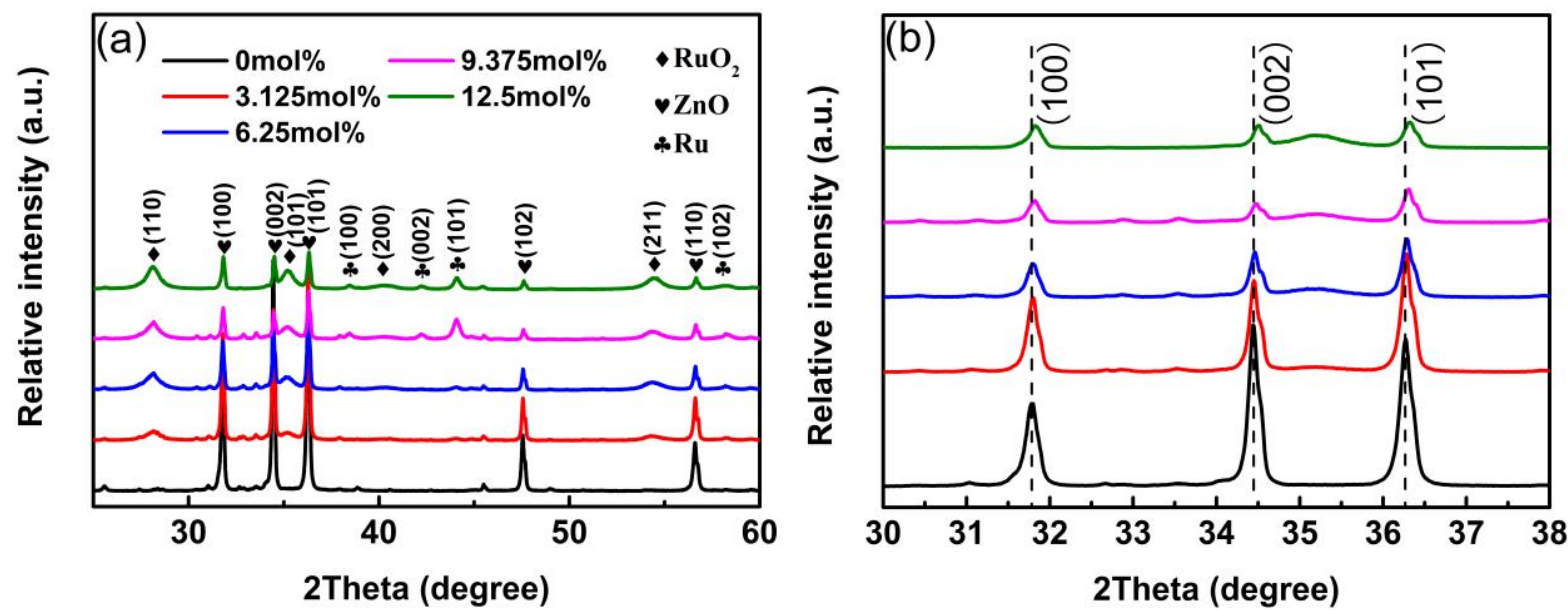

Fig. 3 XRD patterns of $\mathrm{Ru}_{x} \mathrm{Zn}_{1-\mathrm{x}} \mathrm{O} / \mathrm{Ti}$ electrodes (a) $2 \theta$ within $25-60^{\circ}$; (b) enlarged view of $2 \theta$ within 30 $38^{\circ}$. 


\section{Table 1}

The grain size of $\mathrm{Ru}_{\mathrm{x}} \mathrm{Zn}_{1-\mathrm{x}} \mathrm{O} / \mathrm{Ti}$ coatings

\begin{tabular}{cccccc}
\hline The content of $\mathrm{Ru}^{4+}(\mathrm{mol} \%)$ & 0 & 3.125 & 6.25 & 9.375 & 12.5 \\
\hline Grain size $(\mathrm{nm})$ & 33 & 30 & 29 & 28 & 26 \\
\hline
\end{tabular}

According to the results listed in Table 2, the SSA of the of $\mathrm{Ru}_{\mathrm{x}} \mathrm{Zn}_{1-\mathrm{x}} \mathrm{O} / \mathrm{Ti}$ electrodes increased gradually as the $\mathrm{Ru}$ content rose as adding $\mathrm{Ru}$ could reduce the grain size of $\mathrm{ZnO}$ nanorods and increase coatings' irregularity degree, which helped provide more active sites for PEC degradation.

\section{Table 2}

The SSA of $\mathrm{Ru}_{\mathrm{x}} \mathrm{Zn}_{1-\mathrm{x}} \mathrm{O} / \mathrm{Ti}$ coatings

\begin{tabular}{cccccc}
\hline The content of $\mathrm{Ru}^{4+}(\mathrm{mol} \%)$ & 0 & 3.125 & 6.25 & 9.375 & 12.5 \\
\hline $\mathrm{SSA}\left(\mathrm{m}^{2} \mathrm{~g}^{-1}\right)$ & 1.536 & 1.881 & 2.909 & 4.077 & 7.422 \\
\hline
\end{tabular}

The microstructures of the $\mathrm{Ru}_{\mathrm{x}} \mathrm{Zn}_{1-\mathrm{x}} \mathrm{O} / \mathrm{Ti}$ electrodes were analyzed by TEM test. Fig. 4 (a, b) revealed that the wurtzite-type $\mathrm{ZnO}$ nanorods were piled up by the (001) planes, coinciding with its single-crystal characteristic [29]. The SAED pattern shown in Fig. 4 (c) further confirmed that feature and the three diffraction spots corresponded to the (101), (100) and (002) crystal planes of ZnO respectively. According to Fig. 4 (d), the $\mathrm{RuO}_{2}$ nanoparticles distributed on the $\mathrm{ZnO}$ nanorods' surface uniformly, this structure facilitated the transfer of electrons and the separation of photo-generated electrons and holes. The lattice spacing of $0.248 \mathrm{~nm}$ and $0.317 \mathrm{~nm}$ displayed in Fig. 4 (e), corresponded to the (101) crystal plane of $\mathrm{ZnO}$ (JCPDS 36-1451) and the (110) crystal plane of $\mathrm{RuO}_{2}$ (JCPDS 18-1139) respectively. Fig. 4 (f) exhibited the polycrystalline electron diffraction pattern of $\mathrm{ZnO}$ and $\mathrm{RuO}_{2}$, where the two diffraction spots corresponded to the (101) crystal planes of $\mathrm{ZnO}$ and the (110) crystal plane of $\mathrm{RuO}_{2}$ respectively, consistent with the XRD analysis. 


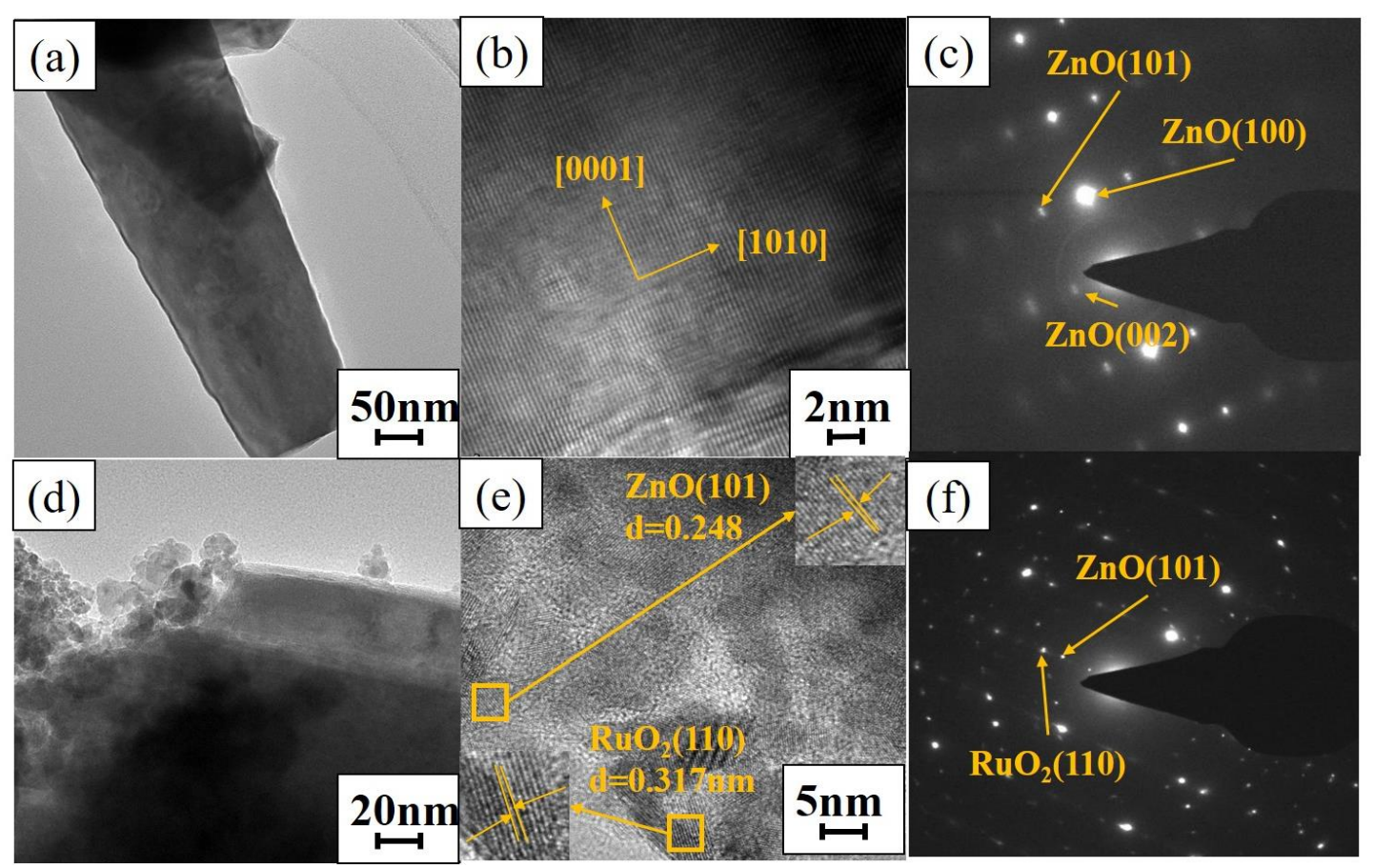

Fig. 4 TEM and SAED patterns of $\mathrm{Ru}_{\mathrm{x}} \mathrm{Zn}_{1-\mathrm{x}} \mathrm{O} / \mathrm{Ti}$ electrodes (a, b, c) $0 \mathrm{~mol} \%$; (d, e, f) $9.375 \mathrm{~mol} \%$.

$\mathrm{X}$-ray photoelectron spectroscopic analysis of $\mathrm{Ru}_{\mathrm{x}} \mathrm{Zn}_{1-\mathrm{x}} \mathrm{O} / \mathrm{Ti}$ electrodes was carried out to identify the elements' composition and valence and the results were adjusted with C1s 284.8 eV. According to the Fig. 5 (a), the full spectra of $\mathrm{Ru}_{\mathrm{x}} \mathrm{Zn}_{1-\mathrm{x}} \mathrm{O} / \mathrm{Ti}$ electrodes have exhibited all the characteristic peaks of Ru3d, Zn2p, O1s and C1s. The high-resolution narrow scan spectra of Ru3d shown in Fig. 5 (b), displayed a pair of narrow characteristic peaks, corresponding to the two spin-orbital components of $\mathrm{Ru} 3 \mathrm{~d} 5 / 2$ and $\mathrm{Ru} 3 \mathrm{~d} 3 / 2$ respectively, which located at 280.48 $\mathrm{eV}$ and $284.98 \mathrm{eV}$ with a spin separation energy of $4.5 \mathrm{eV}$ when the $\mathrm{Ru}$ content was $9.375 \mathrm{~mol} \%$ [36-38]. The Ru3d characteristic peaks could be divided into 5 ones, coinciding with the three existing forms of $\mathrm{Ru}$ ( $\mathrm{RA}$ for $\mathrm{Ru}, \mathrm{RB}$ for $\mathrm{RuO}_{2}$ and $\mathrm{RC}$ for $\mathrm{RuO}_{\mathrm{x}} / \mathrm{Ru}$ ) and $\mathrm{C}$ element. Where peaks at $280.66 \mathrm{eV}$ and $284.91 \mathrm{eV}$ corresponded to $\mathrm{Ru}^{4+}$ in $\mathrm{RuO}_{2}$, obtained by heat treatment after the coatings were exposed to the surrounding environment. The one located at $280.45 \mathrm{eV}$ was consistent with the zero valence of $\mathrm{Ru}^{0}$, resulting from the disproportionation of $\mathrm{RuCl}_{3}$ or the insufficient oxygen supply during the heat treatment. The peak at $282.05 \mathrm{eV}$ indicated the 
existence of $\mathrm{RuO}_{\mathrm{x}} / \mathrm{Ru}$ anoxic ruthenium, and the peak of C1s appeared at $284.8 \mathrm{eV}$ [38-40]. As shown in Table 3, compared with the electrodes with $9.375 \mathrm{~mol} \% \mathrm{Ru}$, the Ru3d characteristic peak of those containing $12.5 \mathrm{~mol} \% \mathrm{Ru}$ red-shifted by $0.12 \mathrm{eV}$, as the $\mathrm{RuO}_{2}$ content decreased and the $\mathrm{RuOx} / \mathrm{Ru}$ content increased [41]. The high-resolution narrow scan spectra of Zn2p in Fig. 5 (c) exhibited two spin orbits, Zn2p3/2 and Zn2p1/2, with a spin separation energy of 23 eV. Pure $\mathrm{ZnO}$ electrodes displayed double peaks of $\mathrm{Zn} 2 \mathrm{p} 3 / 2$ and $\mathrm{Zn} 2 \mathrm{p} 1 / 2$ at $1021.41 \mathrm{eV}$ and $1044.42 \mathrm{eV}$ respectively, corresponding to $\mathrm{Zn}^{2+}$ in $\mathrm{ZnO}[23,42]$. Besides, those peaks blueshifted by $0.42 \mathrm{eV}$ and $0.70 \mathrm{eV}$, when the Ru content was $9.375 \mathrm{~mol} \%(1021.83 \mathrm{eV}$ and 1044.85 $\mathrm{eV})$ and $12.5 \mathrm{~mol} \%(1022.11 \mathrm{eV}$ and $1045.13 \mathrm{eV})$ respectively, due to the replacement between $\mathrm{Zn}^{2+}$ and $\mathrm{Ru}^{4+}$. After the formation of $\mathrm{Zn}-\mathrm{O}-\mathrm{Ru}$ bond, the electron density around $\mathrm{Zn}$ atoms reduced as the electronegativity of $\mathrm{Ru}(2.20)$ was greater than that of $\mathrm{Zn}$ (1.65). Accordingly, the binding energy between the nucleus and extranuclear electrons of $\mathrm{Zn}$ atoms was strengthened, while that of Ru atoms was weakened, which was also one reason for the red shift of Ru3d characteristic peak [23, 43, 44]. The high-resolution narrow scan spectra of O1s were shown in Fig. 5 (d), where the O1s characteristic peaks of pure $\mathrm{ZnO}$ electrode could be divided into two, the peak located at $531.70 \mathrm{eV}$ resulted from adsorbed $\mathrm{O}_{2}$ or $\mathrm{OH}^{-}$ions, while the one at $530.02 \mathrm{eV}$ corresponded to $\mathrm{O}^{2-}$ in $\mathrm{ZnO}$. By contrast, other than the aforementioned peaks, electrodes containing $\mathrm{Ru}$ exhibited another $\mathrm{O} 1 \mathrm{~s}$ characteristic peak at $529.40 \mathrm{eV}$, coinciding with $\mathrm{O}^{2-}$ in $\mathrm{RuO}_{2}$. 

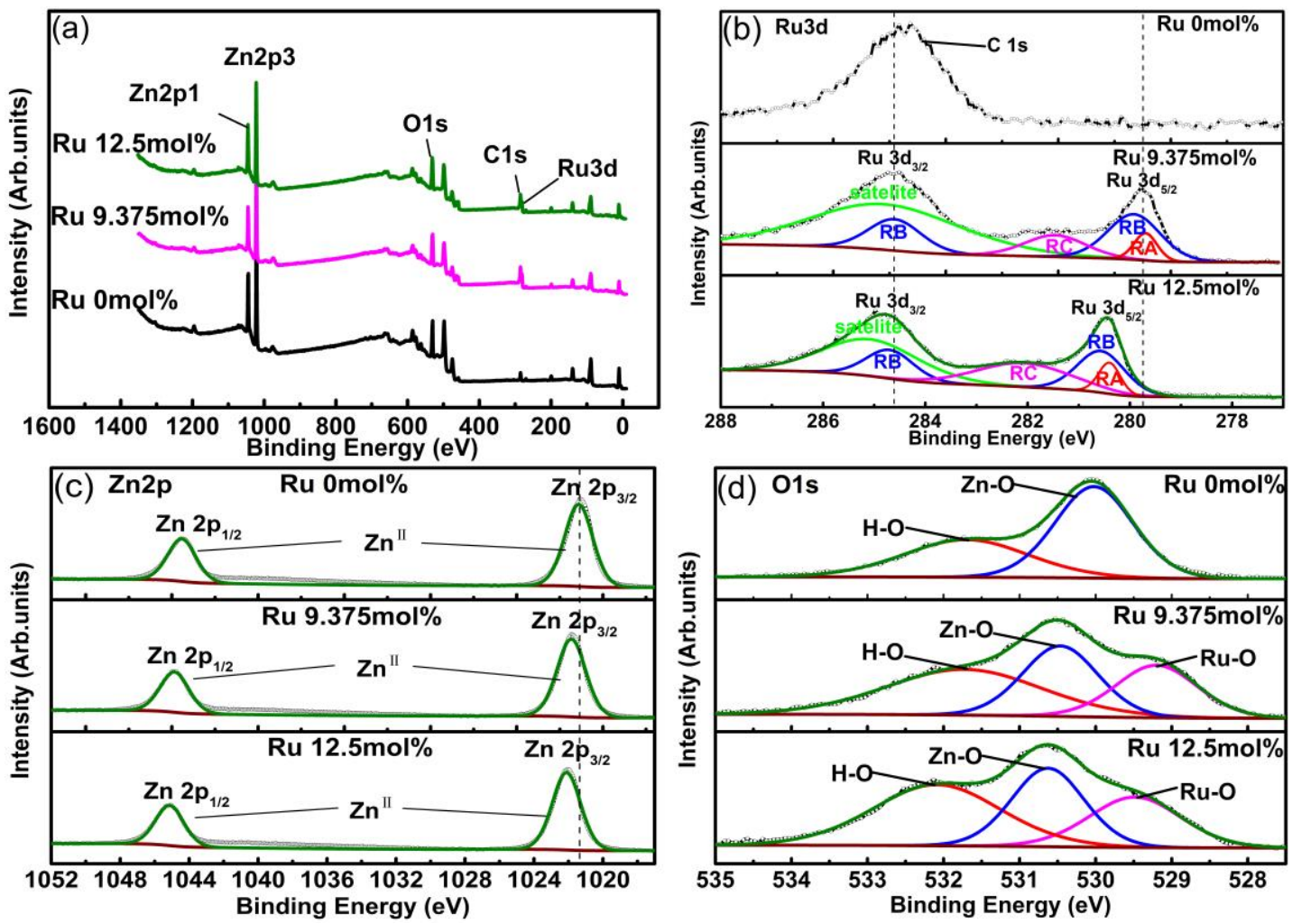

Fig. 5 XPS spectra of $\mathrm{Ru}_{\mathrm{x}} \mathrm{Zn}_{1-\mathrm{x}} \mathrm{O} / \mathrm{Ti}$ coatings (a) full spectra; (b) Ru 3d; (c) $\mathrm{Zn} 2 \mathrm{p}$; (d) O 1s.

Table 3

Peak position and corresponding peak area ratio of XPS spectra of high-resolution Ru3d and Zn2p

\begin{tabular}{ccccc}
\hline \multirow{2}{*}{ Atomic (\%) } & Orbital/spin & Peak position & \multicolumn{2}{c}{ Area under peak (\%) } \\
\cline { 4 - 5 } & & $(\mathrm{eV})$ & $\mathrm{Ru} 9.375 \mathrm{~mol} \%$ & $\mathrm{Ru} 12.5 \mathrm{~mol} \%$ \\
\hline $\mathrm{Ru}$ & $3 \mathrm{~d}_{5 / 2}$ & $280.2 \pm 0.2$ & 0.90 & 1.36 \\
$\mathrm{RuO}_{\mathrm{x}} / \mathrm{Ru}$ & $3 \mathrm{~d}_{5 / 2}$ & $281.9 \pm 0.2$ & 1.88 & 5.64 \\
$\mathrm{RuO}_{2}$ & $3 \mathrm{~d}_{5 / 2}$ & $280.9 \pm 0.2$ & 5.73 & 4.72 \\
$\mathrm{ZnO}$ & $2 \mathrm{P}_{3 / 2}$ & $1021.8 \pm 0.2$ & 91.49 & 88.28 \\
\hline
\end{tabular}

3.2 Band structure and density of state analysis

The effect of $\mathrm{Ru}$ contents on the electronic structure of $\mathrm{Ru}_{\mathrm{x}} \mathrm{Zn}_{1-\mathrm{x}} \mathrm{O}$ solid solution was analyzed by the first-principles calculation, the band and crystal structure characteristics were also explained in detail. According to the data listed in Table 4, the calculated results of this study were very close with other research's. The lattice parameters a, c and unit cell volume $\left(\mathrm{V}_{0}\right)$ of the solid solution all decreased with the increase of $\mathrm{Ru}$ content as the ionic radius of $\mathrm{Ru}$ 
(0.69 $\AA)$ was smaller than that of $\mathrm{Zn}(0.74 \AA)$ [27, 45]. The band structure and density of state (DOS) of $\mathrm{Ru}_{\mathrm{x}} \mathrm{Zn}_{1-\mathrm{x}} \mathrm{O}$ solid solution was shown in Fig. 6. Typically, the Fermi level is close to the central portion of the forbidden band [46]. As reflected in Fig. 6 (a), the minimum calculated energy gap $\left(\mathrm{E}_{\mathrm{g}}\right)$ of pure $\mathrm{ZnO}$ samples was about $1.78 \mathrm{eV}$, though smaller than the experimental value $(3.37 \mathrm{eV})$, the result was still competitive with previous studies by Rafael [47] $(1.87 \mathrm{eV})$ and Bendavid [45] $(1.90 \mathrm{eV})$. A possible reason was that the DFT theory did not take strong coulomb correlation and interaction between electrons into consideration, leading to an underestimated band gap value. As shown in Fig. 6 (a-e), after adding Ru, the conduction band of $\mathrm{ZnO}$ moved down, the valence band moved up, and the impurity level appeared and narrowed the band gap. The higher the Ru contents, the narrower the band gap $(1.44 \mathrm{eV}$ for $3.125 \mathrm{~mol} \%$, $0.72 \mathrm{eV}$ for $6.25 \mathrm{~mol} \%, 0.39 \mathrm{eV}$ for $9.375 \mathrm{~mol} \%, 0.24 \mathrm{eV}$ for $12.5 \mathrm{~mol} \%)$. In other words, the addition of $\mathrm{Ru}$ had a significant effect on the band structure of $\mathrm{ZnO}$, reduced the electrontransfer energy barrier. According to the DOS of the $\mathrm{Ru}_{\mathrm{x}} \mathrm{Zn}_{1-\mathrm{x}} \mathrm{O}$ electrodes shown in Fig. 6 (fj), pure $\mathrm{ZnO}$ samples exhibited peaks in four areas: peaks nearby $-19 \mathrm{eV}$ were mainly caused by the $\mathrm{O} 2 \mathrm{~s}$ orbit, those appeared within the range of -9.5 to $-7.5 \mathrm{eV}$ and -6.5 to $-1.5 \mathrm{eV}$ were resulted from the hybridization of $\mathrm{O} 2 \mathrm{p}$ and $\mathrm{Zn} 3 \mathrm{~d}$ orbits, and peaks located at the conduction band of about $8 \mathrm{eV}$ were mainly formed by $\mathrm{Zn} 4 \mathrm{~s}$ and $\mathrm{O} 2 \mathrm{p}$. A significant difference in the electronic structure between $\mathrm{Ru}$-doped and pure $\mathrm{ZnO}$ samples was that an impurity level appeared in the forbidden bands and narrowed the band gap, due to the electronic states of Ru4d. As the Ru content increased, more electron energy levels appeared near the Fermi level, the electrons became more active and the conductivity was enhanced accordingly. However, with the band gap narrowing down, the recombination rate of photogenerated electron-hole pairs 
also increased.

\section{Table 4}

Comparison of calculated and experimental values of parameters (a and c) and lattice volume $\left(\mathrm{V}_{0}\right)$ of $\mathrm{Ru}_{\mathrm{x}} \mathrm{Zn}_{1-\mathrm{x}} \mathrm{O} / \mathrm{Ti}$ solid solution

\begin{tabular}{|c|c|c|c|c|c|}
\hline & $\mathrm{A}(\AA)$ & $C(\AA)$ & $\alpha, \beta, \gamma\left({ }^{\circ}\right)$ & $\mathrm{V}_{0}(\AA)$ & References \\
\hline \multirow[t]{3}{*}{$\mathrm{ZnO}$} & 3.250 & 5.207 & $90,90,120$ & 47.600 & JCPDS 36-1451 \\
\hline & 3.250 & 5.232 & $90,90,120$ & ---- & Cal. [48] \\
\hline & 3.252 & 5.222 & $90,90,120$ & ---- & Cal. [49] \\
\hline $0 \mathrm{~mol} \%$ & 3.249 & 5.145 & $90,90,120$ & 46.900 & This work \\
\hline $3.125 \mathrm{~mol} \%$ & 3.242 & 5.136 & $89.968,90,120.209$ & 46.348 & This work \\
\hline $6.25 \mathrm{~mol} \%$ & 3.232 & 5.098 & $89.995,90,120.017$ & 46.263 & This work \\
\hline $9.375 \mathrm{~mol} \%$ & 3.226 & 5.077 & $89.018,90.888,121.171$ & 46.200 & This work \\
\hline $12.5 \mathrm{~mol} \%$ & 3.224 & 5.055 & $88.392,91.499,121.249$ & 46.168 & This work \\
\hline
\end{tabular}



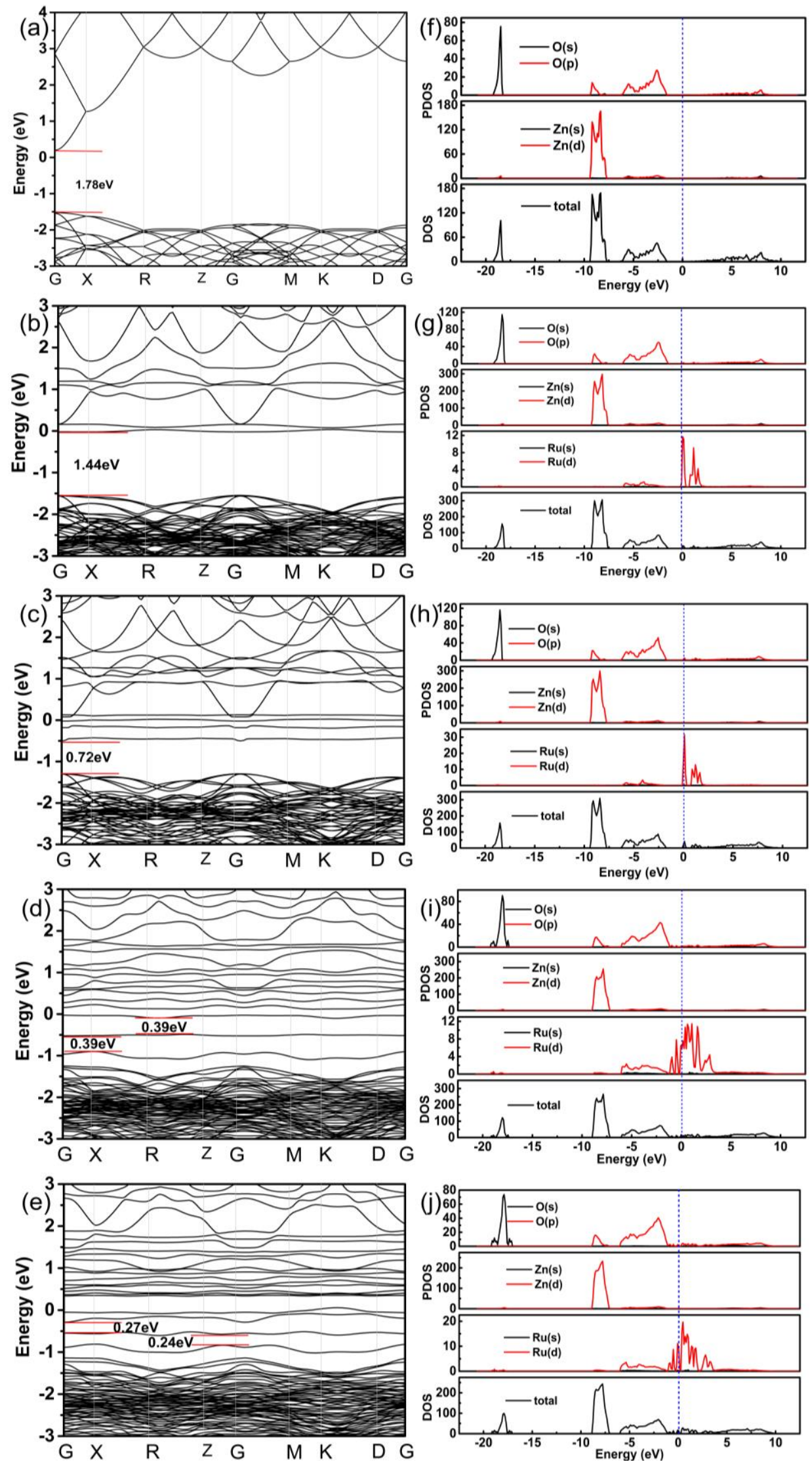

Fig. 6 Band structure and density of state of the $\mathrm{Ru}_{\mathrm{x}} \mathrm{Zn}_{1-\mathrm{x}} \mathrm{O}$ solid solution (a, f) $0 \mathrm{~mol} \%$; (b, g) $3.125 \mathrm{~mol} \%$; (c, h) $6.25 \mathrm{~mol} \%$; (d, i) $9.375 \mathrm{~mol} \%$; (e, j) $12.5 \mathrm{~mol} \%$. 
The UV-DRS tests were performed to observe the forbidden band width of the $\mathrm{Ru}_{\mathrm{x}} \mathrm{Zn}_{1}$ ${ }_{\mathrm{x}} \mathrm{O} / \mathrm{Ti}$ coatings and the value was calculated though the following Tauc-plot method [50]:

$$
\alpha h v=A\left(h v-E_{g}\right)^{1 / n}
$$

Where $\alpha$ is the absorbance index, $\mathrm{h}$ is the Planck constant, $v$ is the frequency, constant $\mathrm{A}$ represents the slope of the Tauc edge, $\mathrm{n}$ equals to $1 / 2$, determined by the semiconductor type, and $E_{g}$ is the band gap, reflected by the intersection point of the linear part of the curve of $(\alpha h v)^{2}$ and the hv axis. According to the results shown in Fig. 7, the band gap (3.12 eV) of pure $\mathrm{ZnO}$ was slightly smaller than the theoretical value $(3.37 \mathrm{eV})$ because of the lack of oxygen [51]. Besides, the band gap decreased with the increase of $\mathrm{Ru}$ contents, coinciding with the theoretical calculation results.
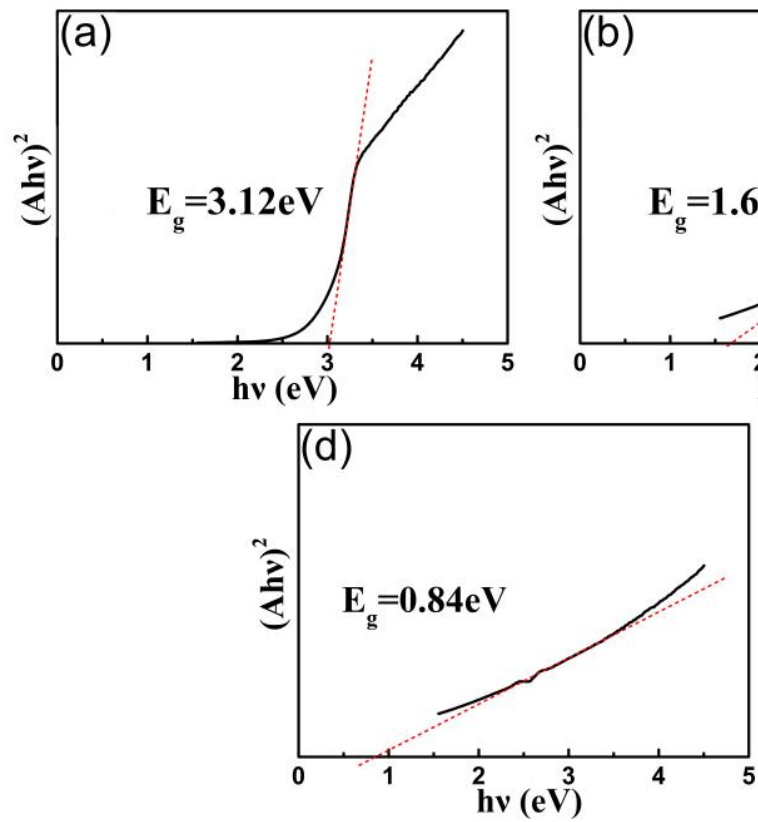
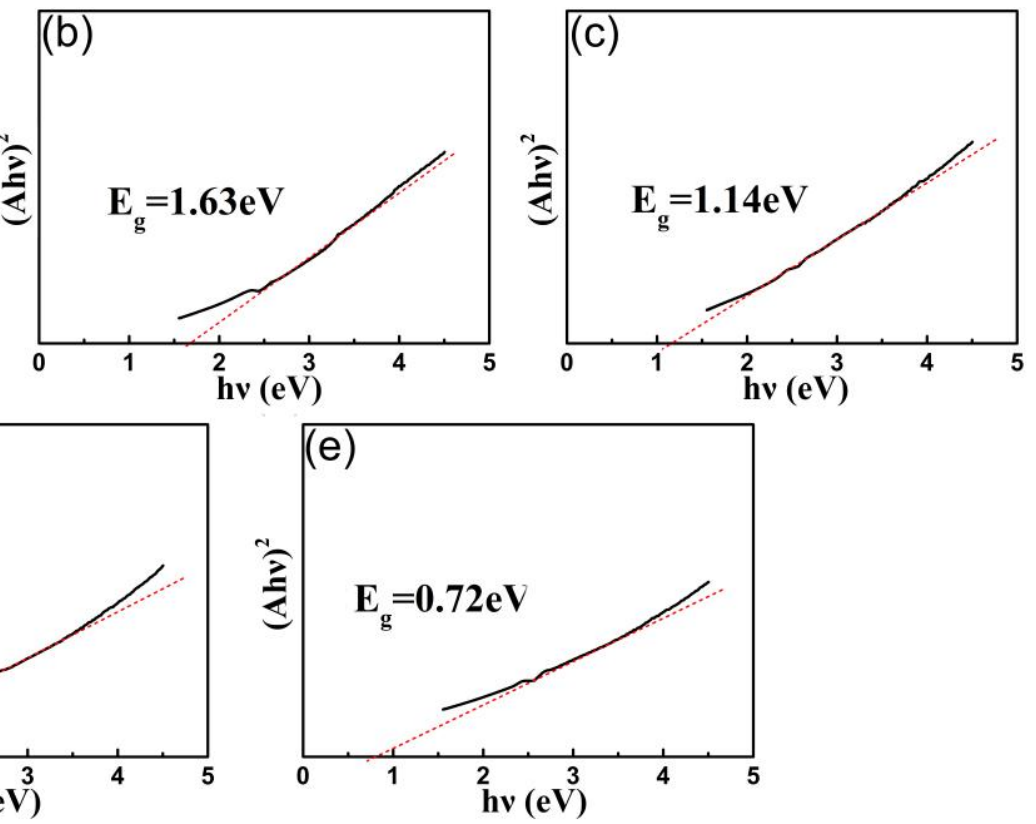

Fig. 7 The UV-DRS patterns of the $\mathrm{Ru}_{x} \mathrm{Zn}_{1-\mathrm{x}} \mathrm{O} / \mathrm{Ti}$ coatings (a) $0 \mathrm{~mol} \%$; (b) $3.125 \mathrm{~mol} \%$; (c) $6.25 \mathrm{~mol} \%$; (d) $9.375 \mathrm{~mol} \%$; (e) $12.5 \mathrm{~mol} \%$.

\subsection{Electrochemical measurements}

As shown in Fig. 8, the LSV test of the $\mathrm{Ru}_{\mathrm{x}} \mathrm{Zn}_{1-\mathrm{x}} \mathrm{O} / \mathrm{Ti}$ electrodes without (a) and with UV 
irradiation (b) were performed at a scanning rate of $10 \mathrm{mV} \mathrm{s}^{-1}$. It could be seen that when the potential exceeded $1.6 \mathrm{~V}$, the current densities increased rapidly thanks to the electrolyzed water. With the rise of Ru contents, the current densities increased first, then decreased, with or without UV irradiation, and reached the maximum when the content was $9.375 \mathrm{~mol} \%$. This was partly because pure $\mathrm{ZnO}$ coatings had a relatively larger band gap and poorer conductivity, leading to a lower current density when voltage remained the same. With the addition of Ru, coatings' band gap decreased and the conductivity was improved, resulting in an increased number of active photo-generated electron-hole pairs and enhanced current density. However, with a $\mathrm{Ru}$ content of $12.5 \mathrm{~mol} \%$, excessive $\mathrm{RuO}_{2}$ particles would pile up on $\mathrm{ZnO}$ nanorods' surface, narrowing its effective light-sensitive area. Besides, the narrowed band gap also resulted in an increased electron-hole recombination rate. As we could see from Fig. 8 (a, b), samples under UV irradiation exhibited stronger current densities due to the generation of photocurrent.
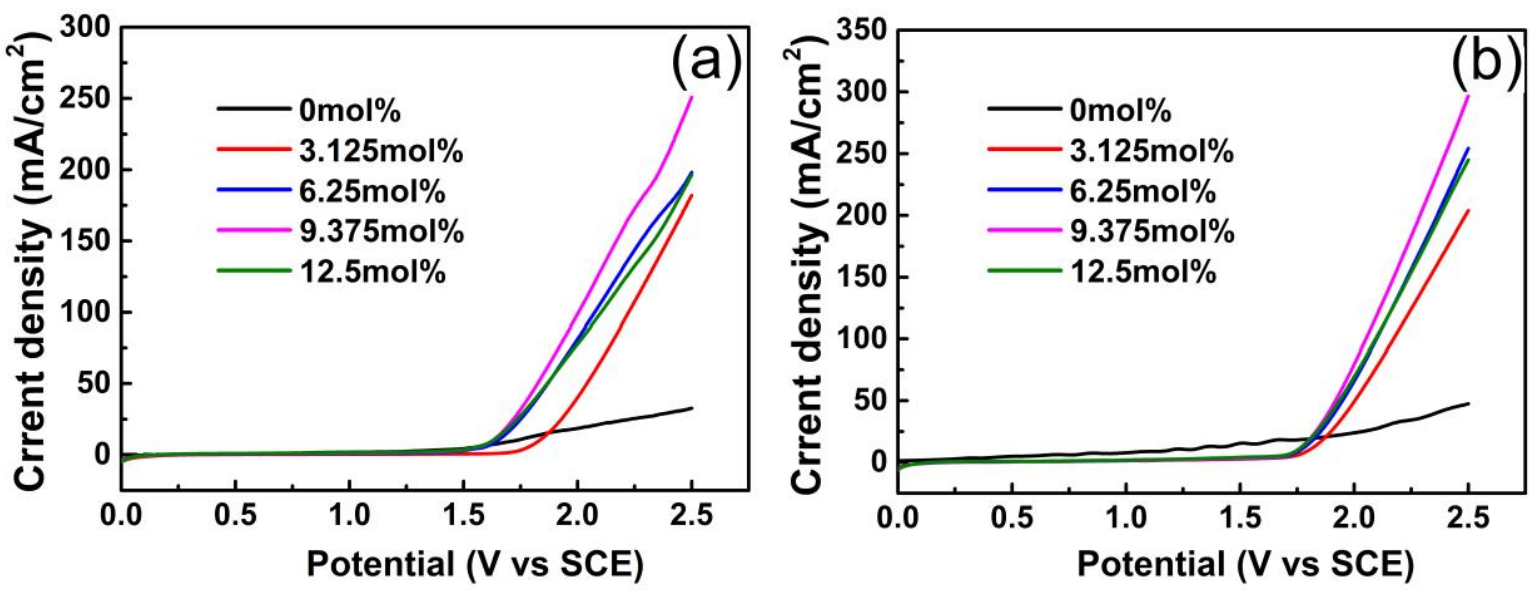

Fig. 8 The LSV curves of the $\mathrm{Ru}_{\mathrm{x}} \mathrm{Zn}_{1-\mathrm{x}} \mathrm{O} /$ Ti electrodes (a) without UV irradiation; (b) with UV irradiation.

Fig. 9 (a) showed the Nyquist plots of the $\mathrm{Ru}_{\mathrm{x}} \mathrm{Zn}_{1-\mathrm{x}} \mathrm{O} / \mathrm{Ti}$ electrodes, and the enlarged view of its high frequency region displayed in Fig. 9 (c), where points and lines referred to the experimental and fitted data respectively. Fig. 9 (b) exhibited the equivalent circuit, in which $\mathrm{L}$ represented the inductive reactance of the electrochemical system, $\mathrm{R}_{\mathrm{s}}$ referred to the 
intersection of the high frequency region and the real axis, reflecting the sum of the solution resistance and the coatings' internal resistance, $R_{f}$ and $R_{c t}$ indicated the coating-substrate or coating-electrolyte resistance and the faraday transfer resistance respectively, $Z_{\mathrm{w}}$ was the Warburg impedance, representing the ionic diffusion process taking place on the interface between the electrodes and electrolyte. Q reflected a constant phase angle element, and $\mathrm{C}_{\mathrm{dI}}$ referred to the double-layer capacitance [52-54]. According to the results, $\mathrm{R}_{\mathrm{S}}$ decreased all the way as the $\mathrm{Ru}$ content increased, indicating a reduced internal resistance. The diameter of the semicircle curve in the high-frequency region reflected the charge-transfer resistance, which decreased first, then increased and reached to the minimum when the $\mathrm{Ru}$ content was $9.375 \mathrm{~mol} \%$, suggesting the electrodes' highest separation rate and transfer efficiency. As shown in Fig. 9 (d), compared with the impedance spectrum of electrodes without UV irradiation, those under the light exhibited a larger inclination degree at the low frequency region, indicating that the UV irradiation accelerated the ion-diffusion rate.
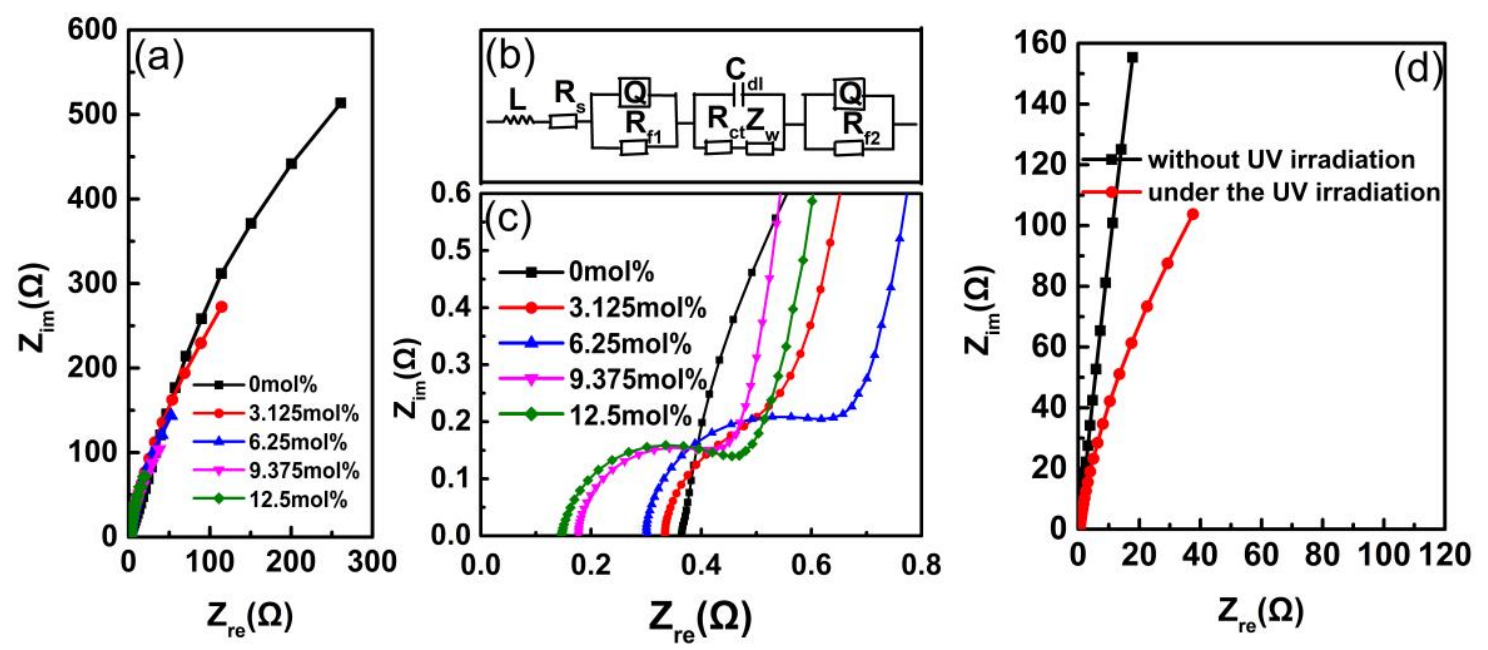

Fig. 9 (a) Nyquist plots of the $\mathrm{Ru}_{\mathrm{x}} \mathrm{Zn}_{1-\mathrm{x}} \mathrm{O} / \mathrm{Ti}$ electrodes; (b) the electrical equivalent circuit for the fitting of the impedance spectra; (c) the enlarged view of the high frequency region of the Nyquist plots; (d) the Nyquist plots with and without UV irradiation. 


\subsection{Photoelectrocatalytic degradation of RhB}

As we could see from the UV-vis absorption spectra and the removal rate of $\mathrm{RhB}$ during PEC degradation process exhibited in Fig. 10 (a-f), the strongest absorption peak of RhB located at $554 \mathrm{~nm}$. And the peaks' intensity decreased as the degradation time increased, the one corresponding to the electrode with $9.375 \mathrm{~mol} \% \mathrm{Ru}$ disappeared first. According to Fig. 10 (f), as the $\mathrm{Ru}$ content rose, the removal rate increased first, from $71 \%$ of the pure $\mathrm{ZnO}$ electrode (120min), then decreased after reaching to the maximum of $97 \%$ (electrode containing $9.375 \mathrm{~mol} \% \mathrm{Ru}$ ), indicating that doping appropriate amount of $\mathrm{Ru}$ could significantly improve electrodes' degradation efficiency. The TOC test results shown in Fig. 10 (g) confirmed that the addition of Ru could improve the TOC removal rate effectively, which exhibited an inverted Ushaped curve and reached to the maximum of $68 \%$ when the Ru content was $9.375 \mathrm{~mol} \%$. This was partly because the shortage of wide forbidden band of pure $\mathrm{ZnO}$ coatings and related problems including relatively smaller light-sensitive area and lower yield of photogenerated carriers could be overcome by adding $\mathrm{Ru}$. Meanwhile, the $\mathrm{RuO}_{2}$ particles growing on $\mathrm{ZnO}$ surface provided an efficient electron-transfer channel and reduced the recombination rate of photogenerated electron-hole pairs. And the coatings' surface became less smooth with the addition of $\mathrm{Ru}$, providing more active sites. However, with a Ru content of $12.5 \mathrm{~mol} \%$, excessive $\mathrm{RuO}_{2}$ particles wrapped around $\mathrm{ZnO}$ surface, hindering the irradiation of ultraviolet light. Though the forbidden band width of $\mathrm{ZnO}$ decreased after adding $\mathrm{Ru}$, undersized band gap could accelerate the recombination rate of photogenerated electron-hole pairs in turn. That explained why the electrodes containing $9.375 \mathrm{~mol} \% \mathrm{Ru}$ exhibited the highest degradation rate.

In order to further illustrate the effect of $\mathrm{Ru}$ content on the degradation rate, the 
degradation kinetic analysis was carried out under the direction of the following first-order kinetic equation [55]:

$$
-\ln \left(\frac{\mathrm{C}_{0}}{\mathrm{C}}\right)=\mathrm{kt}
$$

Where $\mathrm{C}_{0}$ is the initial concentration of the $\mathrm{RhB}$ solution $\left(20 \mathrm{mg} \mathrm{L}^{-1}\right), \mathrm{C}$ is the concentration of $\mathrm{RhB}$ for a given degradation time, $\mathrm{k}$ is the reaction rate constant $\left(\mathrm{min}^{-1}\right)$, and $\mathrm{t}$ is the reaction time. As the $\mathrm{Ru}$ content rose, $\mathrm{k}$ value increased first, then decreased, and reached to the maximum of 0.03 when the content was $9.375 \mathrm{~mol} \%$, indicating the electrodes' highest removal rate.
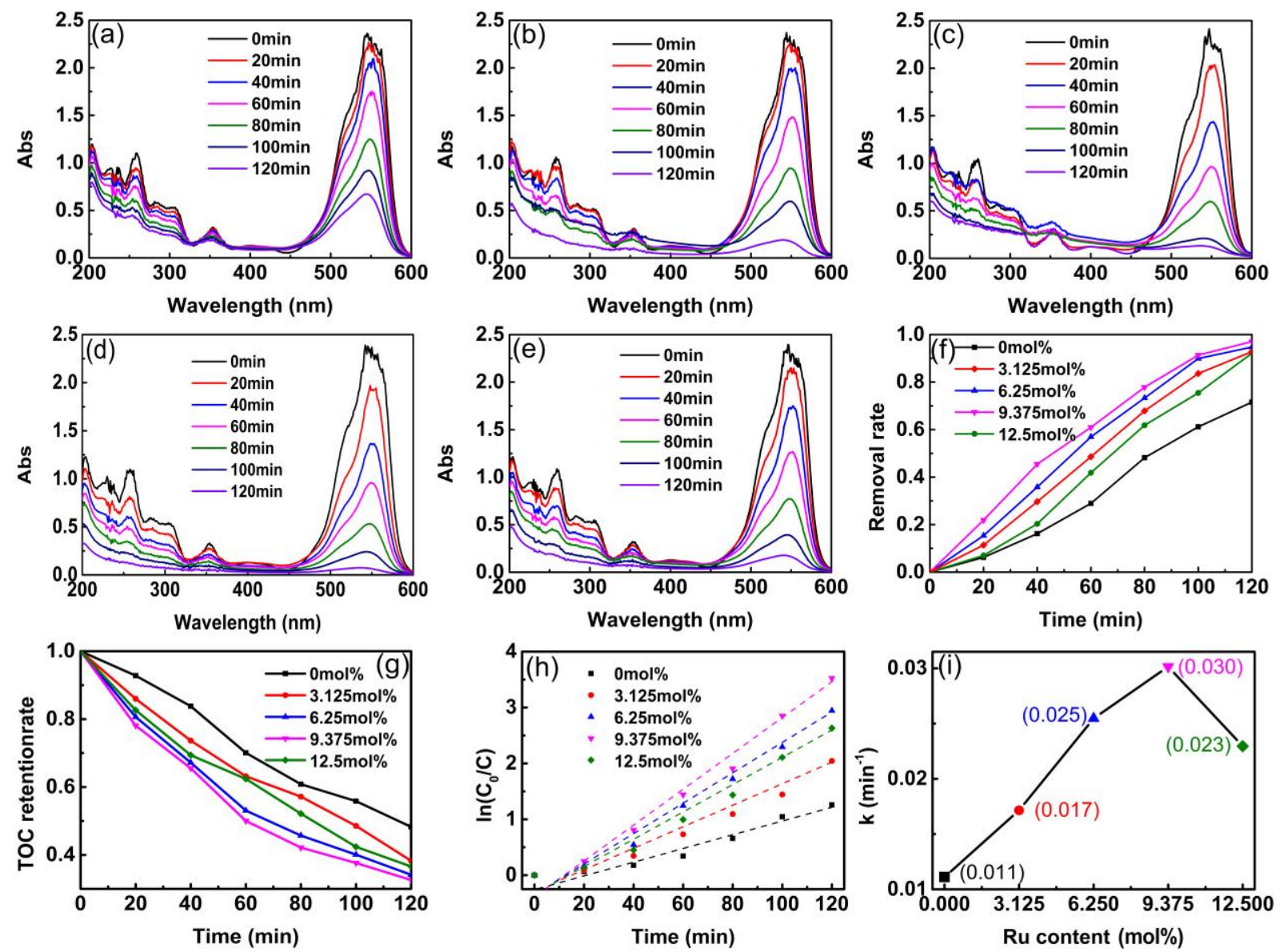

Fig. $10 \mathrm{UV}$-vis absorption spectra of $\mathrm{Ru}_{\mathrm{x}} \mathrm{Zn}_{1-\mathrm{x}} \mathrm{O} / \mathrm{Ti}$ electrodes under PEC degradation with different intervals (a) $0 \mathrm{~mol} \%$; (b) $3.125 \mathrm{~mol} \%$; (c) $6.25 \mathrm{~mol} \%$; (d) $9.375 \mathrm{~mol} \%$; (e) $12.5 \mathrm{~mol} \%$; along with (f) removal 
ratio of $\mathrm{RhB}$; (g) removal ratio of TOC; (h) degradation kinetics; (i) the reaction rate constant.

To make further explanation, the $\mathrm{PC}$ and $\mathrm{EC}$ degradation tests of $\mathrm{Ru}_{\mathrm{x}} \mathrm{Zn}_{1-\mathrm{x}} \mathrm{O} / \mathrm{Ti}$ electrodes containing $9.375 \mathrm{~mol} \% \mathrm{Ru}$ were also performed respectively, and the results were shown in Fig. 11. With a degradation time of $120 \mathrm{~min}$, the removal rates of EC, $\mathrm{PC}$ and $\mathrm{PEC}$ were $12 \%, 50 \%$, and $97 \%$ respectively, the much higher PEC efficiency confirmed the synergy effect of EC and PC degradation. According to the test results displayed in Fig. 11 (g), after 120 min of degradation, the TOC removal rates for $\mathrm{PEC}, \mathrm{PC}$, and $\mathrm{EC}$ were $68 \%, 44 \%$, and $10 \%$, respectively. Compared with EC, the photogenerated electron-hole pairs generated during PEC process, the holes could decompose RhB directly, and oxidize hydroxide ions on the electrodes' surface into hydroxyl radicals, which would oxidize $\mathrm{RhB}$ in turn. Compared with $\mathrm{PC}, \mathrm{PEC}$ was provided with an external power source and the $\mathrm{RuO}_{2}$ particles on the $\mathrm{ZnO}$ surface acting as an electro-transfer channel, offered more active sites for electrocatalysis and helped separate the photogenerated electron-hole pairs. In addition, a bias potential of $2.5 \mathrm{~V}$ facilitated the oxygen evolution reaction, providing the oxygen needed to oxidize $\mathrm{RhB}$. It could be seen from Fig. 11 $(\mathrm{e}, \mathrm{f})$ that the regression curve basically accorded with first-order kinetics, and the rate constant of PEC $\left(0.030 \mathrm{~min}^{-1}\right)$ was much larger than that of EC $\left(0.001 \mathrm{~min}^{-1}\right)$ and PC $\left(0.006 \mathrm{~min}^{-1}\right)$, confirming the synergy effect of PEC degradation again. As shown in Fig. 11 (h, i), the degradation rate of Ti plate was only $15.3 \%$ after $120 \mathrm{~min}$, therefore, its effect on the $\mathrm{Ru}_{\mathrm{x}} \mathrm{Zn}_{1}$ ${ }_{\mathrm{x}} \mathrm{O} / \mathrm{Ti}$ electrodes' degradation rate could be ignored. 

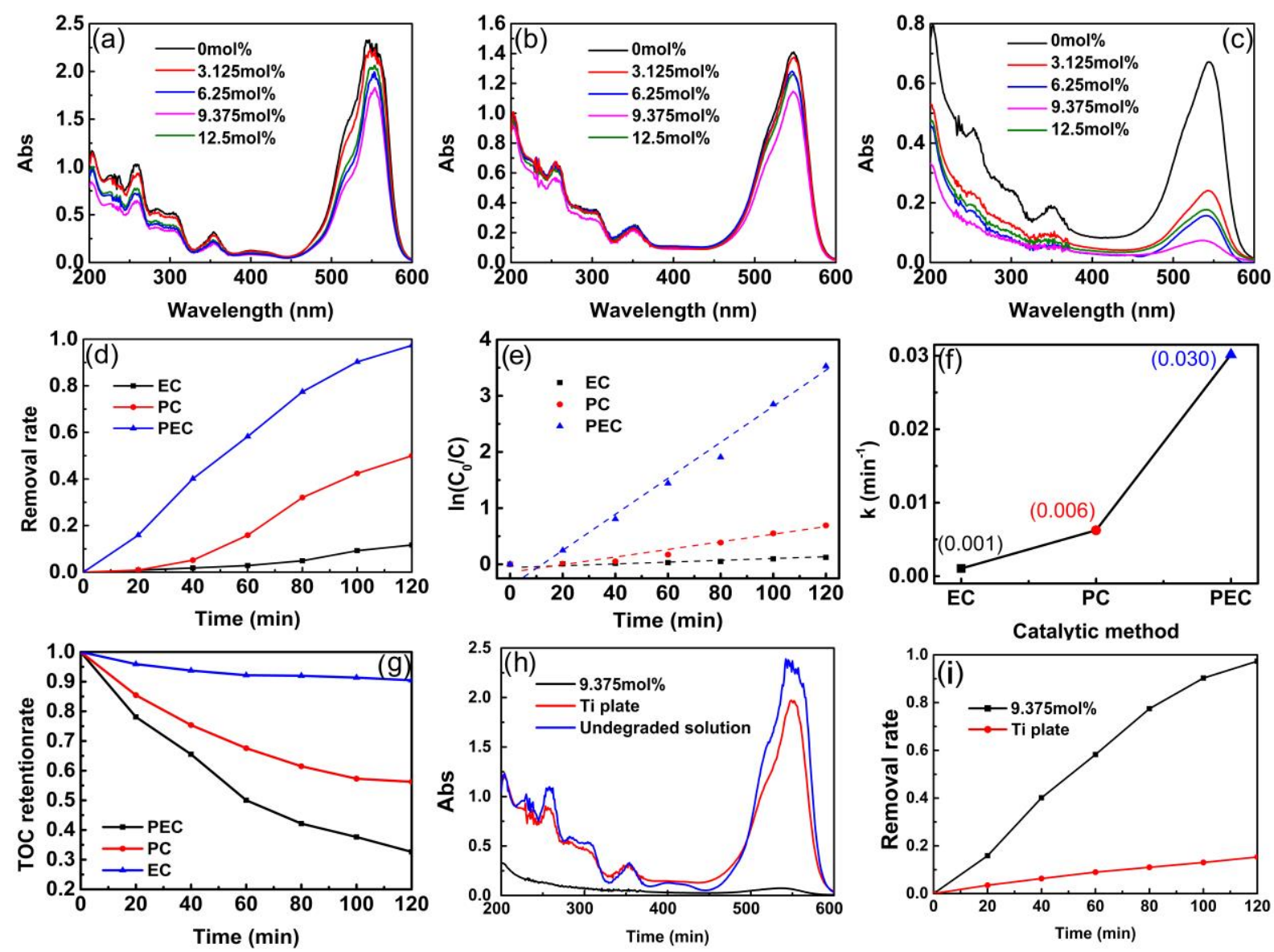

Fig. 11 UV-visible absorption spectra of $\mathrm{Ru}_{\mathrm{x}} \mathrm{Zn}_{1-\mathrm{x}} \mathrm{O} / \mathrm{Ti}$ electrodes containing of $9.375 \mathrm{~mol} \% \mathrm{Ru}$ with

different catalytic methods (a) EC; (b) PC; (c) PEC; (d) removal rates of PEC, PC and EC; (e) degradation kinetics; (f) reaction rate constant; (g) TOC removal rates of PEC, PC and EC; (h) Comparison UV-visible absorption specta after 120 min degradation; (i) removal rates of electrodes containing $9.375 \mathrm{~mol} \% \mathrm{Ru}$ and Ti plates.

\subsection{Photoelctrocatalytic mechanism}

The model shown in Fig. 13 could further illustrate the effect of $\mathrm{Ru}$ contents on $\mathrm{ZnO}$ nanorods in terms of the electron transfer and the mechanism of PEC degradation. It has been found that the photogenerated electron-hole pairs generated only when photons with energy of no less than the band gap were absorbed. To some extent, the large band gap of $\mathrm{ZnO}$ limited the number of photogenerated electron holes. However, the Ru-doped $\mathrm{ZnO}$ exhibited a conduction 
band energy reduced from E1 to E3, while the valence band energy increased from E2 to E4, and the impurity energy level appeared in the band gap, which decreased the energy band width and expanded the light-absorption area. Besides, $\mathrm{RuO}_{2}$ particles growing on $\mathrm{ZnO}$ nanorods' surface offered an efficient electron-transfer channel and more active sites $[56,57]$. Together with the external power source, it could propel the photo-generated electrons to transfer towards the counter electrode, thus increased the separation rate of the photogenerated electron-hole pairs significantly. Furthermore, those electrons could react with molecular oxygen and generate superoxide radicals, which then reacted with hydrogen ions and generated hydroxyl radicals in turn [58]. Meanwhile, the holes could decompose the organic dyes directly, and oxidize hydroxide ions into hydroxyl radicals [59]. Together, those holes and hydroxyl radicals degraded $\mathrm{RhB}$ into harmless compounds such as $\mathrm{H}_{2} \mathrm{O}$ and $\mathrm{CO}_{2}[60,61]$. The following were specific chemical formulas:

$$
\begin{gathered}
\mathrm{ZnO}+\mathrm{hv} \longrightarrow \mathrm{ZnO}+\mathrm{h}^{+}+\mathrm{e}^{-} \\
\mathrm{e}^{-}+\mathrm{O}_{2} \longrightarrow \cdot \mathrm{O}_{2}^{-} \\
\mathrm{O}_{2}^{-}+2 \mathrm{e}^{-}+2 \mathrm{H}^{+} \longrightarrow 2 \cdot \mathrm{OH} \\
\mathrm{h}^{+}+\mathrm{OH}^{-} \longrightarrow \cdot \mathrm{OH} \\
\mathrm{h}^{+} / \cdot \mathrm{OH}+\mathrm{RhB} \longrightarrow \mathrm{CO}_{2}+\mathrm{H}_{2} \mathrm{O} \\
\mathrm{RuO}_{2}[]+\mathrm{h}^{+}+\mathrm{H} \mathrm{O}_{2} \longrightarrow \mathrm{RuO}_{2}[\cdot \mathrm{OH}]+\mathrm{H}^{+} \\
\mathrm{RuO}_{2}[\cdot \mathrm{OH}]+\mathrm{RhB} \longrightarrow \mathrm{RuO}_{2}[]+\mathrm{CO}_{2}+\mathrm{H}_{2} \mathrm{O}
\end{gathered}
$$




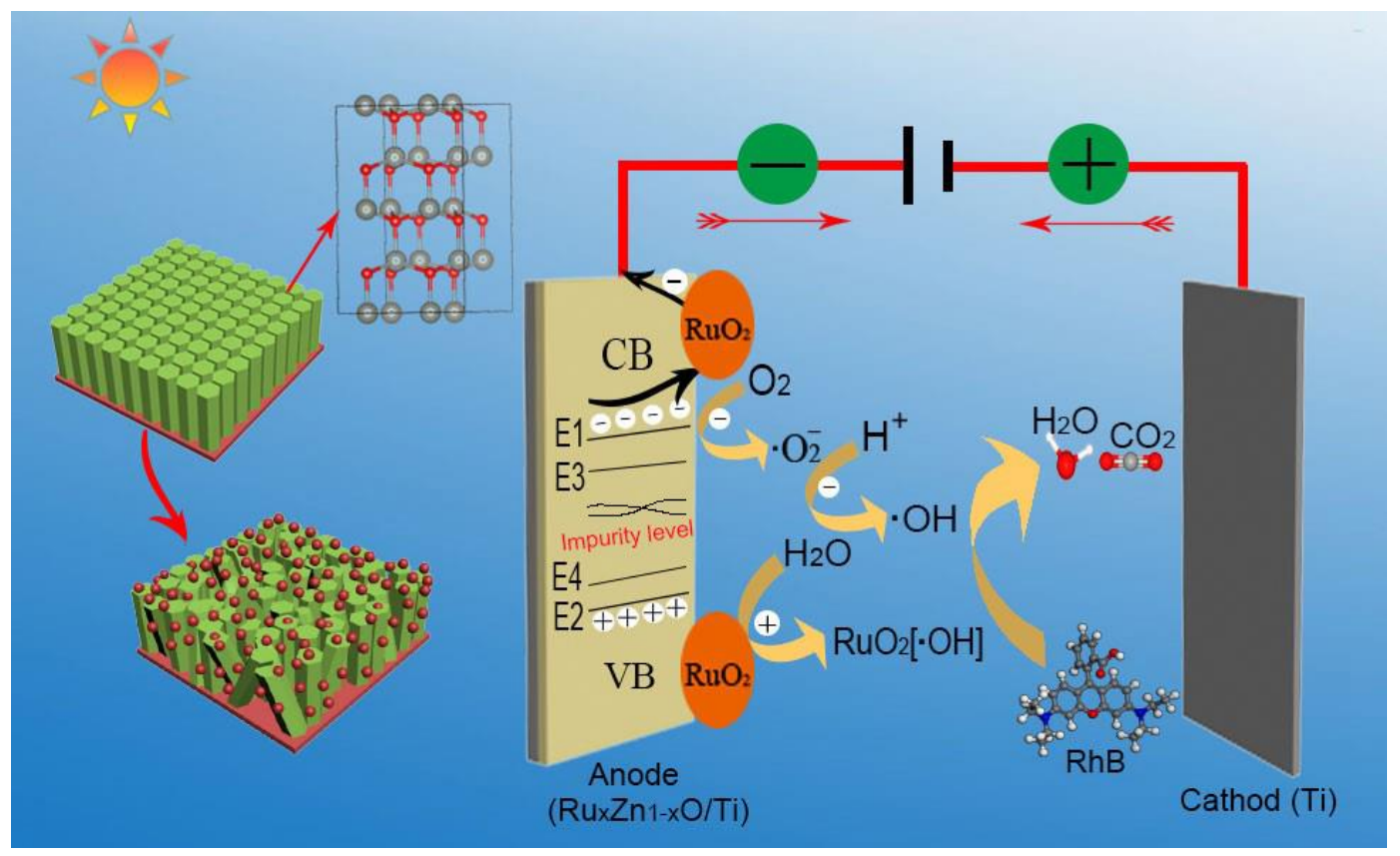

Fig. 13 Schematic microstructure model and PEC mechanism of $\mathrm{Ru}_{\mathrm{x}} \mathrm{Zn}_{1-\mathrm{x}} \mathrm{O} / \mathrm{Ti}$ electrodes.

\section{Conclusion}

$\mathrm{Ru}_{\mathrm{x}} \mathrm{Zn}_{1-\mathrm{x}} \mathrm{O} / \mathrm{Ti}$ electrodes with excellent PEC performance were prepared through simple thermal decomposition method. It has been found that $\mathrm{Ru}$-doped $\mathrm{ZnO}$ exhibited a smaller forbidden band width as a number of $\mathrm{Zn}^{2+}$ and $\mathrm{Ru}^{4+}$ exchanged placed in $\mathrm{ZnO}$ lattice, and the amount of photogenerated carriers increased accordingly. The rest of $\mathrm{Ru}$ existed on $\mathrm{ZnO}$ nanorods' surface in the form of $\mathrm{RuO}_{2}$ particles acting as an electron-transfer channel, together with the external bias, it propelled photogenerated electrons to transfer to the counter electrode and reduced the recombination rate of electron-hole pairs. Meanwhile, with the addition of Ru, the grain size of $\mathrm{ZnO}$ nanorods decreased and the coatings' surface became less smooth, leading to larger specific surface area as well as more active sites. The accessory oxygen evolution reaction could also accelerate the oxidation of the dye. However, with excessive Ru content, $\mathrm{RuO}_{2}$ particles could wrap $\mathrm{ZnO}$ nanorods around and hinder the irradiation of ultraviolet light, reducing the PEC efficiency. Indeed, the band gap decreased with the addition of Ru, but 
undersized band gap could accelerate the recombination rate of photogenerated electron-hole pairs. That explained why the electrodes with $9.375 \mathrm{~mol} \%$ rather than those containing $12.5 \mathrm{~mol} \%$ $\mathrm{Ru}$ exhibited the best PEC performance.

\section{Acknowledgments}

This research was completed with the support of the National Natural Science Foundation of China (83418083) and the Natural Science Foundation of Fujian Province (2019J01230). 


\section{References}

[1] Weber EJ, Adams RL. Chemical-mediated and sediment-mediated reduction of the azo-dye disperse-blue79. Environ Sci Technol 1995, 29: 1163-1170.

[2] Zhang FL, Zhao JC, Shen T, et al. $\mathrm{TiO}_{2}$-assisted photodegradation of dye pollutants-II. Adsorption and degradation kinetics of eosin in $\mathrm{TiO}_{2}$ dispersions under visible light irradiation. Appl Catal B-Environ. 1998, 15, 147-156.

[3] Afzaal M, Malik MA, O'Brien P. Preparation of zinc containing materials. New J Chem 2007, 31, 20292040.

[4] Kamat PV. Meeting the clean energy demand: Nanostructure architectures for solar energy conversion. J Phys Chem C 2007, 111, 2834-2860.

[5] Roshan A, Joseph C, Ittyachen MA, Growth and characterization of a new metal-organic crystal: potassium thiourea bromid. Mater Let 2001, 49, 299-302.

[6] Vayssieres L. Growth of arrayed nanorods and vanowires of $\mathrm{ZnO}$ from aqueous solutions. Adv Mater 2003, 15, 464-466.

[7] Kumar SG, Rao K. Zinc oxide based photocatalysis: tailoring surface-bulk structure and related interfacial charge carrier dynamics for better environmental applications. Rsc Advances 2015, 5, 3306-3351.

[8] Kim KJ, Kreider PB, Choi C, et al. Visible-light-sensitive na-doped p-type flower-like ZnO photocatalysts synthesized via a continuous flow microreactor. Rsc Advances 2013, 3, 12702-12710.

[9] Lee JC, Park S, Park HJ, et al. Photocatalytic degradation of TOC from aqueous phenol solution using solution combusted $\mathrm{ZnO}$ nanopowders. J Electroceram 2009, 22, 110-113.

[10] Khassin AA, Yurieva TM, Kaichev VV, et al. Metal-support interactions in cobalt-aluminum coprecipitated catalysts: XPS and CO adsorption studies. J Mol Catal A-Chem 2001, 175, 189-204.

[11] Gomes YF, Freitas AK, Nascimento RM, et al. Experimental statistic design applied for obtaining Zn:Xce by microwave-assisted hydrothermal method with photocatalytic property. J Adv Ceram 2016, 5, $103-110$.

[12] Xiong Y, Tang ZL, Wang Y, et al. Gas sensing capabilities of $\mathrm{TiO}_{2}$ porous nanoceramics prepared through premature sintering. J Adv Ceram 2015, 4, 152-157

[13] Chai $\mathrm{SN}$, Zhao GH, Li PQ, et al. Novel sieve-like $\mathrm{SnO}_{2} / \mathrm{TiO}_{2}$ nanotubes with integrated photoelectrocatalysis: Fabrication and application for efficient toxicity elimination of nitrophenol wastewater. J Phys Chem C 2011, 115, 18261-18269.

[14] Wang X, Zhao HM, Quan X, et al. Visible light photoelectrocatalysis with salicylic acid-modified $\mathrm{TiO}_{2}$ nanotube array electrode for p-nitrophenol degradation. J Hazard Mater 2009, 166, 547-552.

[15] Dai GP, Yu JG, Liu G. Synthesis and enhanced visible-light photoelectrocatalytic activity of p-n junction $\mathrm{BiOI} / \mathrm{TiO}_{2}$ nanotube arrays. J Phys Chem C 2011, 115, 7339-7346.

[16] Wang XQ, Zhou YN, Li R, et al. Removal of Hg-0 from a simulated flue gas by photocatalytic oxidation on $\mathrm{Fe}$ and $\mathrm{Ce}$ co-doped $\mathrm{TiO}_{2}$ under low temperature. Chem Eng J 2019, 360, 1530-1541.

[17] Zhao SW, Zuo HF, Guo YR, et al. Carbon-doped ZnO aided by carboxymethyl cellulose: Fabrication, photoluminescence and photocatalytic applications. J Alloys Compd 2017, 695, 1029-1037.

[18] Zhao W, Zhong Q, Pan YX, et al. Systematic effects of S-doping on the activity of $\mathrm{V}_{2} \mathrm{O}_{5} / \mathrm{TiO}_{2}$ catalyst for low-temperature $\mathrm{NH}_{3}$-SCR. Chem Eng J 2013, 228, 815-823.

[19] Kayani ZN, Anjum M, Riaz S, et al. Role of Mn in biological, optical, and magnetic properties ZnO nano-particles. Appl Phys A: Mater. Sci Process 2020, 126, 197.

[20] Ashebir ME, Tesfamariam GM, Nigussie GY, et al. Structural, optical, and photocatalytic activities of 
Ag-doped and Mn-doped ZnO nanoparticles. J Nanomater 2018, 2018, 938-947.

[21] Qiu YF, Fan HB, Tan GP, et al. Effect of nitrogen doping on the photo-catalytic properties of nitrogen doped ZnO tetrapods. Mater Lett 2014, 131, 64-66.

[22] Ditta MA, Farrukh MA, Ali S, et al. X-ray peak profiling, optical parameters and catalytic properties of pure and CdS doped ZnO-NiO nanocomposites. Russ J Appl Chem 2017, 90, 151-159.

[23] Etacheri V, Roshan R, Kumar V. Mg-doped ZnO nanoparticles for efficient sunlight-driven photocatalysis. ACS Appl Mater Interfaces 2012, 4, 2717-2725.

[24] Han J, An HJ, Kim TW, et al. Effect of structure-controlled ruthenium oxide by nanocasting in electrocatalytic oxygen and chlorine evolution reactions in acidic conditions. Catalysts 2019, 9, 549.

[25] Peng F, Zhou CM, Wang HJ, et al. The role of $\mathrm{RuO}_{2}$ in the electrocatalytic oxidation of methanol for direct methanol fuel cell. Catal Commun 2009, 10, 533-537.

[26] Yue H, Xue LZ, Chen F. Efficiently electrochemical removal of nitrite contamination with stable $\mathrm{RuO}_{2}-$ $\mathrm{TiO}_{2} /$ Ti electrodes. Appl Catal B 2017, 206, 683-691.

[27] Dalal B, Sarkar B, De SK. Itinerant to localized electronic behavior in phase segregated ruthenates. J Alloys Compd 2016, 667, 248-254.

[28] Mariolacos K. The Role of The role of electronegativity in solid solution formation: An addendum. Neues Jahrb Mineral Monatsh 2003, 5, 215-221.

[29] Liu ZF, E L, Ya J, et al. Growth of ZnO nanorods by aqueous solution method with electrodeposited ZnO seed layers. Appl Surf Sci 2009, 255, 6415-6420.

[30] Alam U, Khan A, Raza W, et al. Highly efficient Y and V co-doped ZnO photocatalyst with enhanced dye sensitized visible light photocatalytic activity. Catal Today 2017, 284, 169-178.

[31] Gomez-Pozos H, Gonzalez-Vidal JL, Torres GA, et al. Castaneda, Chromium and ruthenium-doped zinc oxide thin films for propane sensing applications. Sensors 2013, 13, 3432-3444.

[32] Khan MAM, Kumar S, Alhazaa AN, et al. Al-Gawati, Modifications in structural, morphological, optical and photocatalytic properties of $\mathrm{ZnO}: \mathrm{Mn}$ nanoparticles by sol-gel protocol. Mater Sci Semicond Process 2018, 87, 134-141.

[33] Son HS, Choi NJ, Kim KB, et al. Al-doped $\mathrm{ZnO}$ seed layer-dependent crystallographic control of $\mathrm{ZnO}$ nanorods by using electrochemical deposition. Mater Res Bull 2016, 82, 50-54.

[34] Deraz NM. Effects of heat treatment on physicochemical properties of cerium based nickel system. J Anal Appl Pyrolysis 2012, 95, 56-60.

[35] Deraz NM. Effect of NiO content on structural, surface and catalytic characteristics of nano-crystalline $\mathrm{NiO} / \mathrm{CeO}_{2}$ system. Ceram Int 2012, 38, 747-753.

[36] Chan HYH, Takoudis CC, Weaver MJ. High-pressure oxidation of ruthenium as probed by surfaceenhanced Raman and X-ray photoelectron spectroscopies. J Catal 1997, 172, 336-345.

[37] Kleiman-Shwarsctein A, Laursen AB, Cavalca F, et al. A general route for $\mathrm{RuO}_{2}$ deposition on metal oxides from $\mathrm{RuO}_{4}$. Chem Commun 2012, 48, 967-969.

[38] Wang FZ, Xu Q, Tan ZA, et al. Efficient polymer solar cells with a solution-processed and thermal annealing-free $\mathrm{RuO}_{2}$ anode buffer layer. J Mater Chem A 2014, 2, 1318-1324.

[39] Ananth A, Dharaneedharan S, Gandhi MS, et al. Novel $\mathrm{RuO}_{2}$ nanosheets-Facile synthesis, characterization and application. Chem Eng J 2013, 223, 729-736.

[40] Cox PA, Goodenough JB, Tavener PJ, et al. The electronic structure of $\mathrm{Bi}_{2-\mathrm{x}} \mathrm{Gd}_{\mathrm{x}} \mathrm{Ru}_{2} \mathrm{O}_{7}$ and $\mathrm{RuO}_{2}$ : A study by electron spectroscopy. J Solid State Chem 1986, 62, 360-370.

[41] Kwak I, Kwon IS, Kim J, et al. $\mathrm{IrO}_{2}-\mathrm{ZnO}$ hybrid nanoparticles as highly efficient trifunctional electrocatalysts. J Phys Chem C 2017, 121, 14899-14906. 
[42] Jing LQ, Xu ZL, Shang J, et al. The preparation and characterization of ZnO ultrafine particles. Materials Science and Engineering a-Mater Sci Eng A 2002, 332, 356-361.

[43] Karamat S, Rawat RS, Tan TL, et al. Exciting dilute magnetic semiconductor: Copper-doped ZnO. J Supercond Novel Magn 2013, 26, 187-195.

[44] Kostova B, Konstantinov L. Factors determining optical absorption of variously doped single crystals of $\mathrm{Bi}_{12} \mathrm{SiO}_{20}$. J Phys Conf Ser 2010, 253, 012029.

[45] Bendavid LI, Carter EA, First principles study of bonding, adhesion, and electronic structure at the $\mathrm{Cu}_{2} \mathrm{O}(111) / \mathrm{ZnO}(10(1)$ over-bar0) interface. Surf Sci 2013, 618, $62-71$.

[46] Shao YQ, Chen ZJ, Zhu JQ, et al. Relationship between electronic structures and capacitive performance of the electrode material $\mathrm{IrO}_{2}-\mathrm{ZrO}_{2}$. J Am Ceram Soc 2016, 99, 2504-2511.

[47] Gonzalez-Hernandez R, Perez WL, Rodriguez MJA. Electronic structure and magnetism in $\mathrm{Ni}_{0.0625} \mathrm{Zn}_{0.9375} \mathrm{O}$ : An ab initio study. J Magn Magn Mater 2009, 321, 2547-2549.

[48] Wu HC, Peng YC, Chen CC. Effects of Ga concentration on electronic and optical properties of Gadoped $\mathrm{ZnO}$ from first principles calculations. Opt Mater 2013, 35, 509-515.

[49] Lakel S, Elhamra F, Almi K, et al. First-principles investigation of electronic and optical properties and thermodynamic stability of $\mathrm{Zn}_{1-\mathrm{x}} \mathrm{Be}_{\mathrm{x}} \mathrm{O}$ semiconductor alloy. Mater Sci Semicond Process 2015, 40, 803-810.

[50] Davis EA, Mott NF. Conduction in non-crystalline systems V. Conductivity, optical absorption and photoconductivity in amorphous semiconductors. Philos Mag 1970, 22, 0903-0922.

[51] Liu HY, Zeng F, Lin YS, et al. Correlation of oxygen vacancy variations to band gap changes in epitaxial ZnO thin films. Appl Phys Lett 2013, 102, 181908.

[52] Chen ZJ, Zhu JQ, Zhang S, et al. Influence of the electronic structures on the heterogeneous photoelectrocatalytic performance of Ti/ $\mathrm{Ru}_{\mathrm{x}} \mathrm{Sn}_{1-\mathrm{x}} \mathrm{O}_{2}$ electrodes. J Hazard Mater 2017, 333, 232-241.

[53] Zhang X, Wang JM, Liu J, et al. Design and preparation of a ternary composite of graphene oxide/carbon dots/polypyrrole for supercapacitor application: Importance and unique role of carbon dots. Carbon 2017, $115,134-146$.

[54] Shao YQ, Yi ZY, He C, et al. Effects of annealing temperature on the structure and capacitive performance of nanoscale Ti//rO $\mathrm{Ir}_{2}-\mathrm{ZrO}_{2}$ electrodes. J Am Ceram Soc 2015, 98, 1485-1492.

[55] Vaiano V, Matarangolo M, Murcia JJ, et al. Enhanced photocatalytic removal of phenol from aqueous solutions using ZnO modified with Ag. Appl Catal B 2018, 225, 197-206.

[56] Boudenne JL, Cerclier O, Galea J, et al. Electrochemical oxidation of aqueous phenol at a carbon black slurry electrode, Appl. Catal., A 1996, 143, 185-202.

[57] Comninellis C. Electrocatalysis in the electrochemical conversion/combustion of organic pollutants for waste-water treatment. Electrochim Acta 1994, 39, 1857-1862.

[58] Pelegrini R, Peralta-Zamora P, de Andrade AR, et al. Electrochemically assisted photocatalytic degradation of reactive dyes. Appl Catal B 1999, 22, 83-90.

[59] Konstantinou IK, Albanis $\mathrm{TA}$. $\mathrm{TiO}_{2}$-assisted photocatalytic degradation of azo dyes in aqueous solution: kinetic and mechanistic investigations - A review. Appl Catal B 2004, 49, 1-14.

[60] Himebaugh R, Smith M. Semi-micro tube method for chemical oxygen demand. Anal Chem 1979, 51, 1085-1087.

[61] Wei L, Zhu H, Mao XH, et al. Electrochemical oxidation process combined with UV photolysis for the mineralization of nitrophenol in saline wastewater. Sep Purif Technol 2011, 77, 18-25. 
Figures

(a)

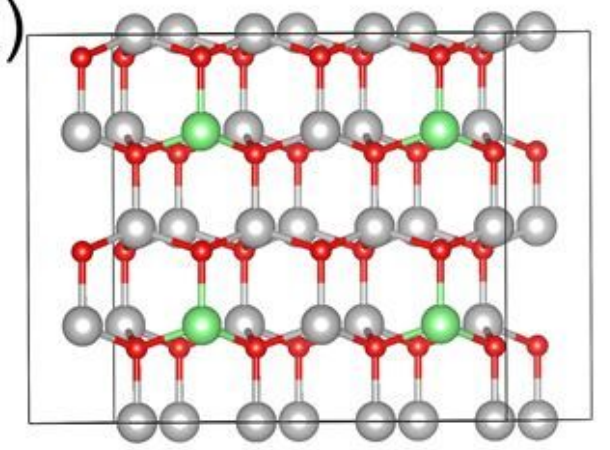

(b)

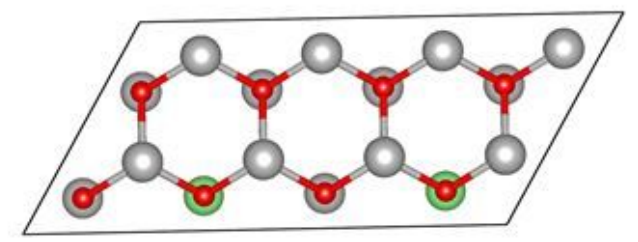

(c)

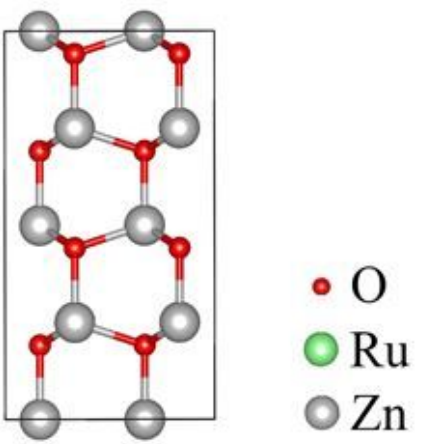

Figure 1

Ru-doped ZnO with hexagonal wurtzite crystal structure (a) front view; (b) top view; (c) left view. 2.4 Electrochemical measurements 

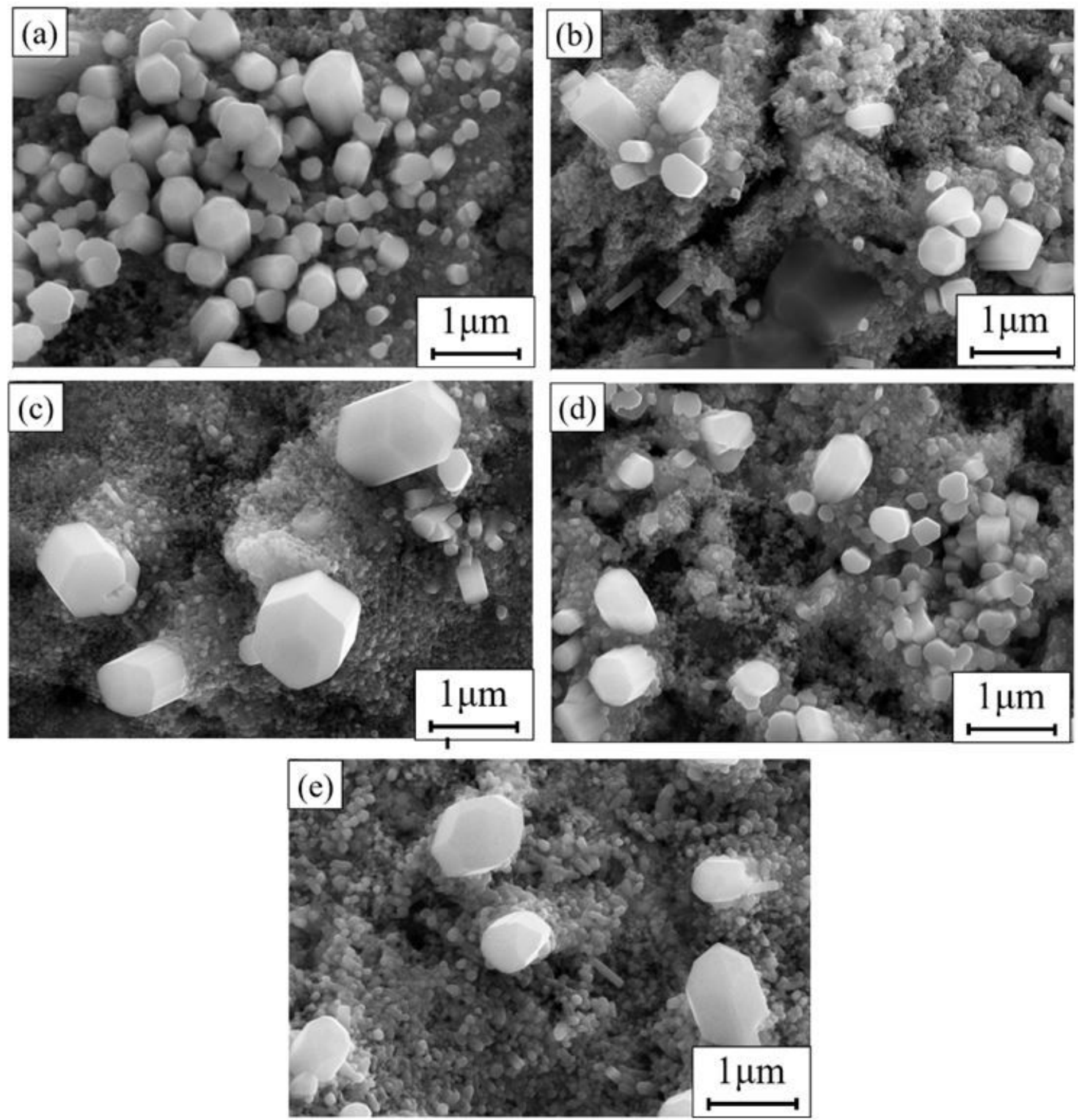

Figure 2

SEM images of RuxZn1-xO/Ti electrodes (a) 0mol\%; (b) 3.125mol\%; (c) $6.25 \mathrm{~mol} \%$; (d) $9.375 \mathrm{~mol} \%$; (e) $12.5 \mathrm{~mol} \%$. 

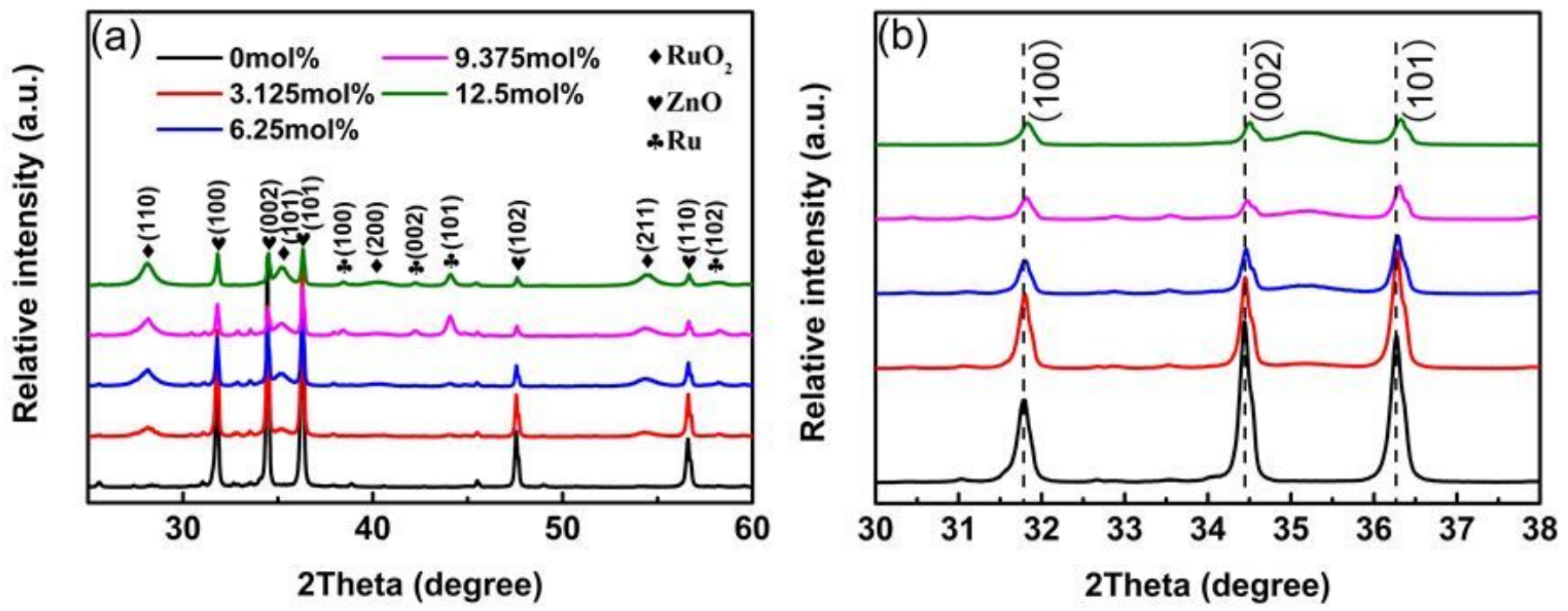

Figure 3

XRD patterns of RuxZn1-xO/Ti electrodes (a) $2 \theta$ within $25-60^{\circ}$; (b) enlarged view of $2 \theta$ within $30-38^{\circ}$.

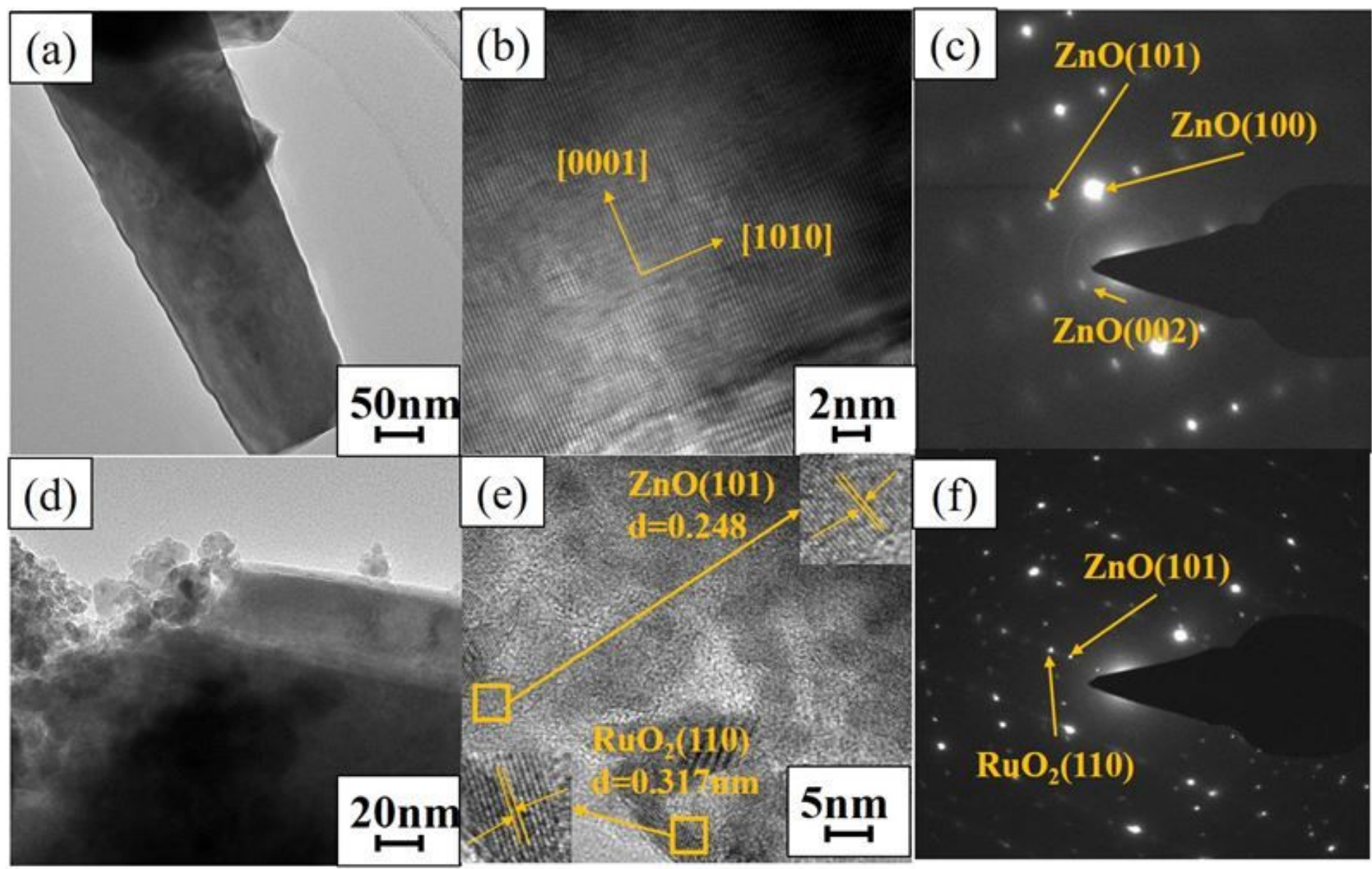

Figure 4

TEM and SAED patterns of RuxZn1-xO/Ti electrodes (a, b, c) 0mol\%; (d, e, f) $9.375 \mathrm{~mol} \%$. 

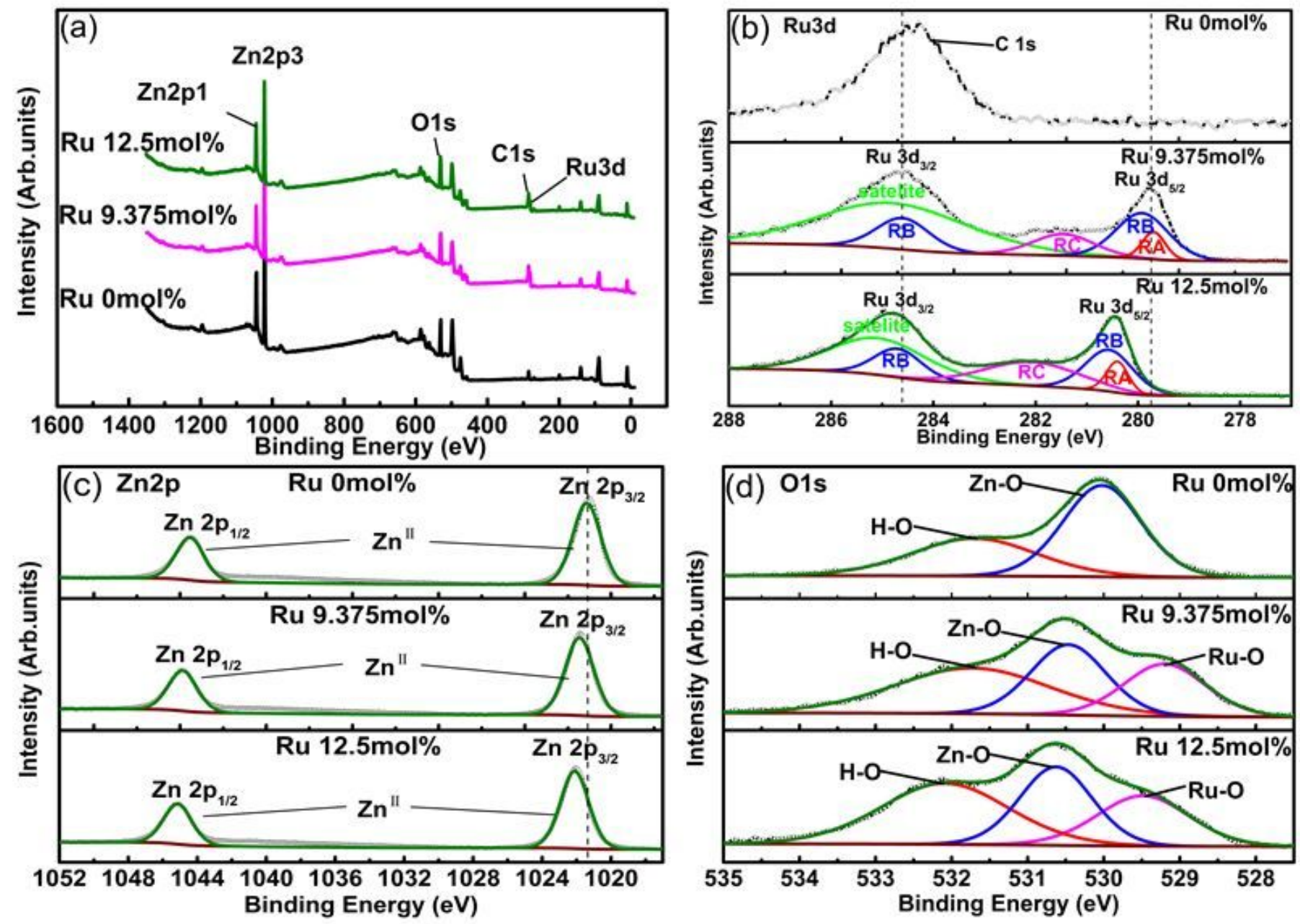

Figure 5

XPS spectra of RuxZn1-xO/Ti coatings (a) full spectra; (b) Ru 3d; (c) Zn 2p; (d) 0 1s. 

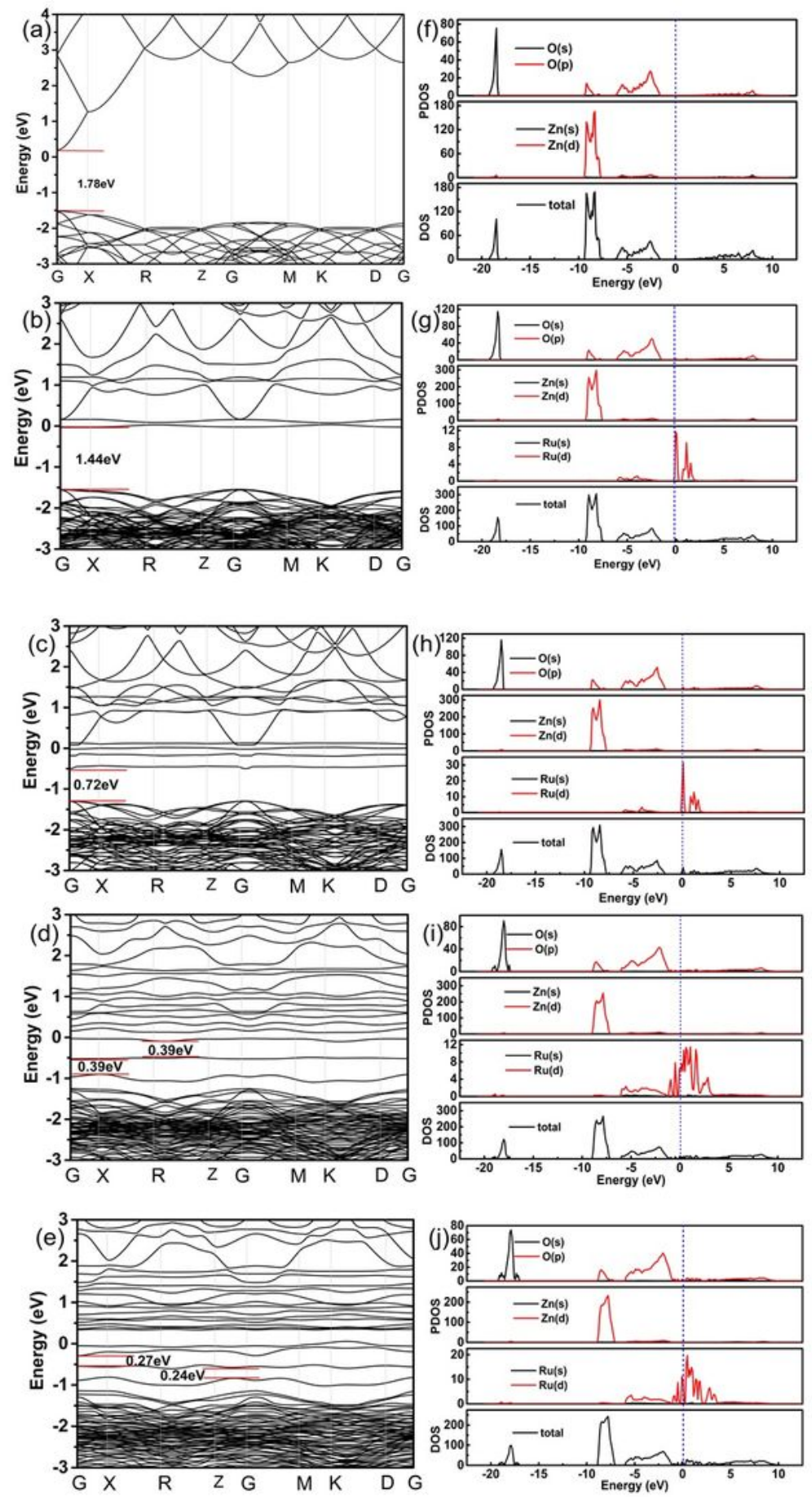

\section{Figure 6}

Band structure and density of state of the RuxZn1-xO solid solution $(a, f) 0 \mathrm{~mol} \%$; $(b, g) 3.125 \mathrm{~mol} \% ;(c, h)$ $6.25 \mathrm{~mol} \%$; (d, i) $9.375 \mathrm{~mol} \%$; (e, j) $12.5 \mathrm{~mol} \%$. 

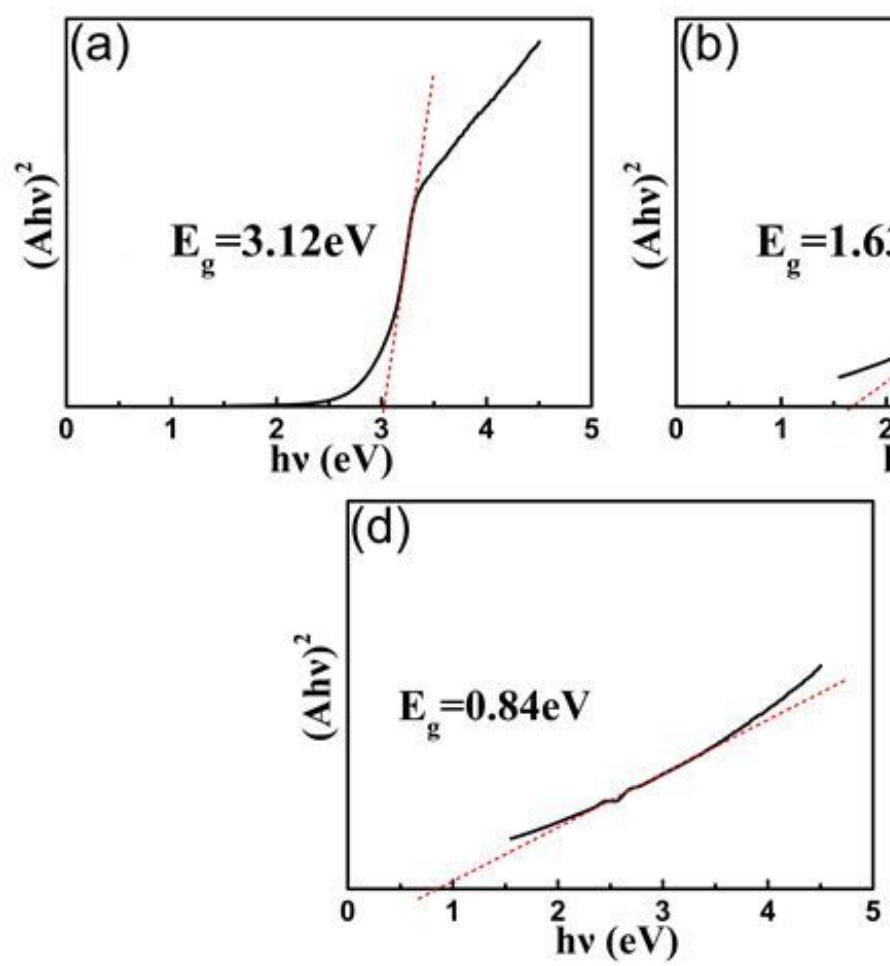
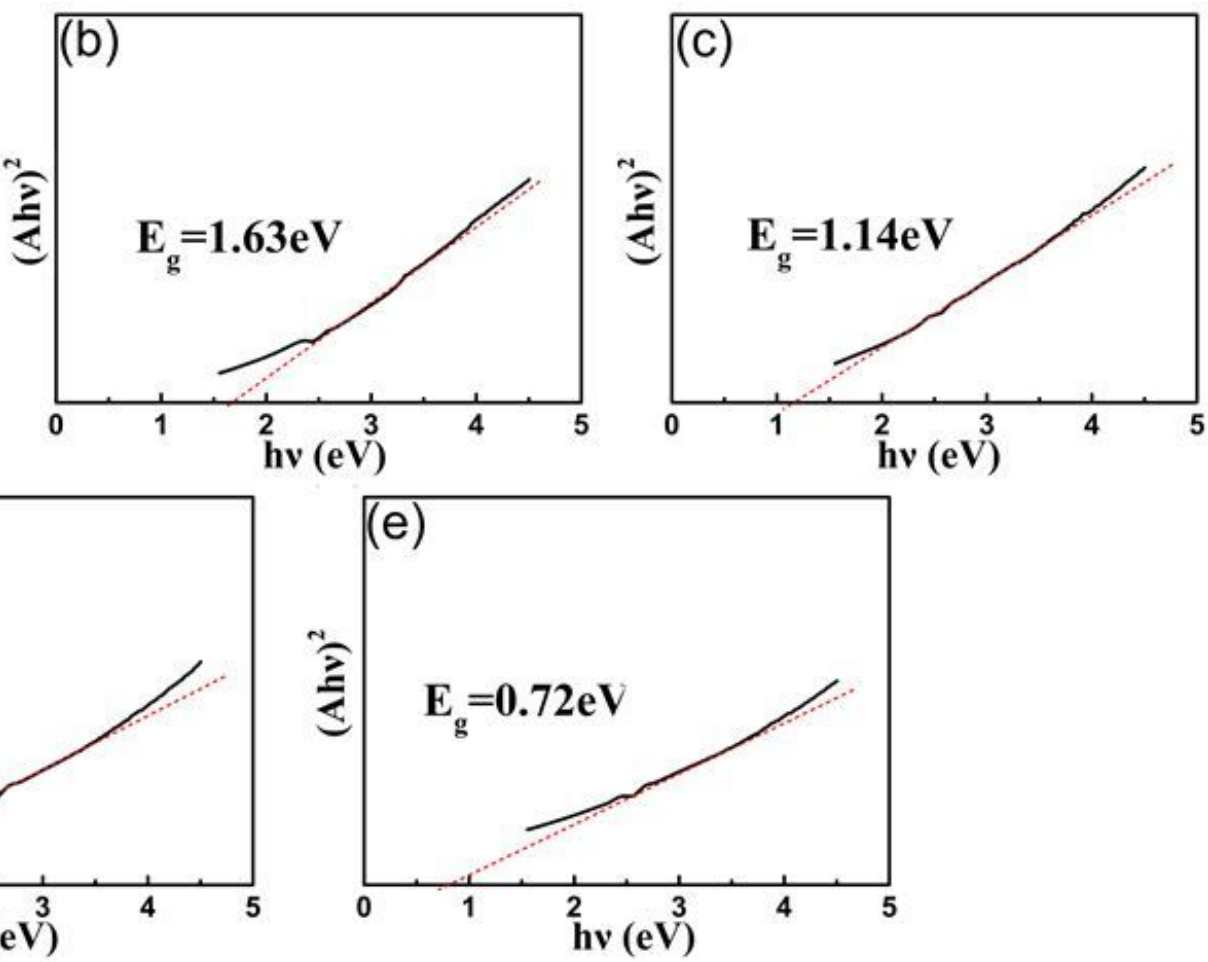

Figure 7

The UV-DRS patterns of the RuxZn1-xO/Ti coatings (a) $0 \mathrm{~mol} \%$; (b) $3.125 \mathrm{~mol} \%$; (c) $6.25 \mathrm{~mol} \%$; (d) $9.375 \mathrm{~mol} \%$; (e) $12.5 \mathrm{~mol} \%$.
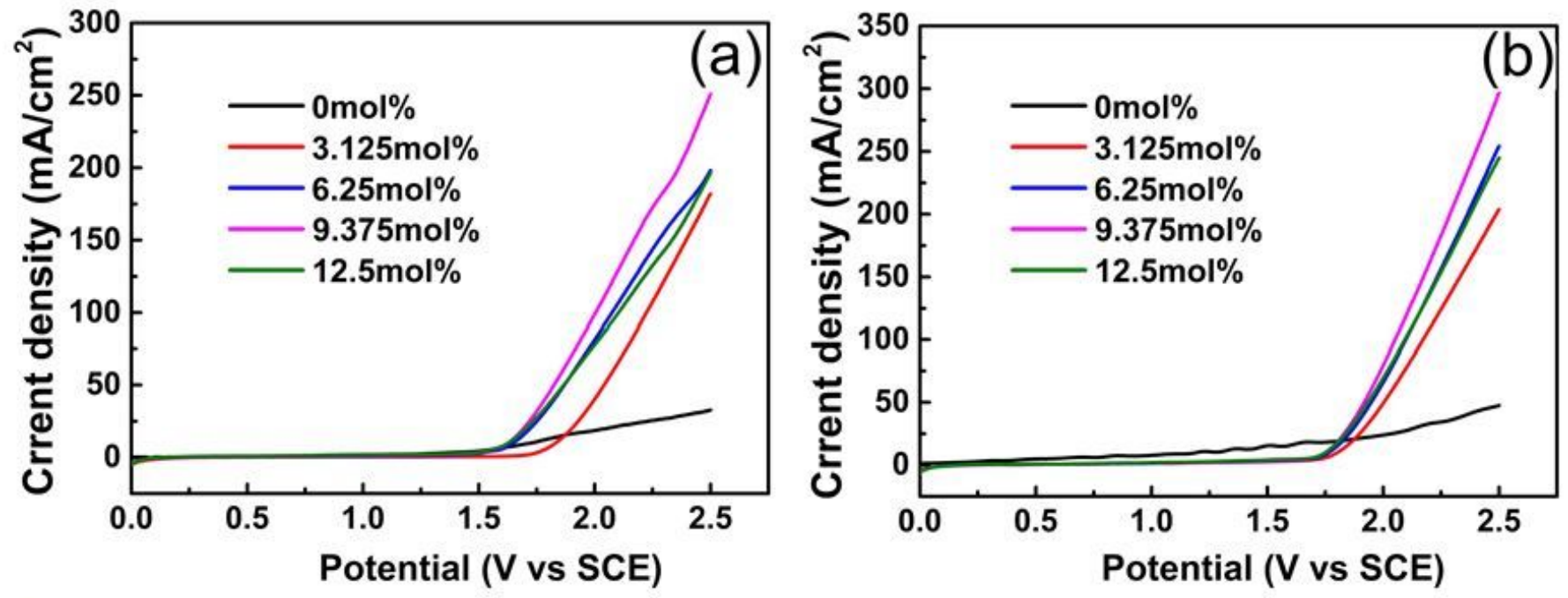

Figure 8

The LSV curves of the RuxZn1-xO/Ti electrodes (a) without UV irradiation; (b) with UV irradiation. 

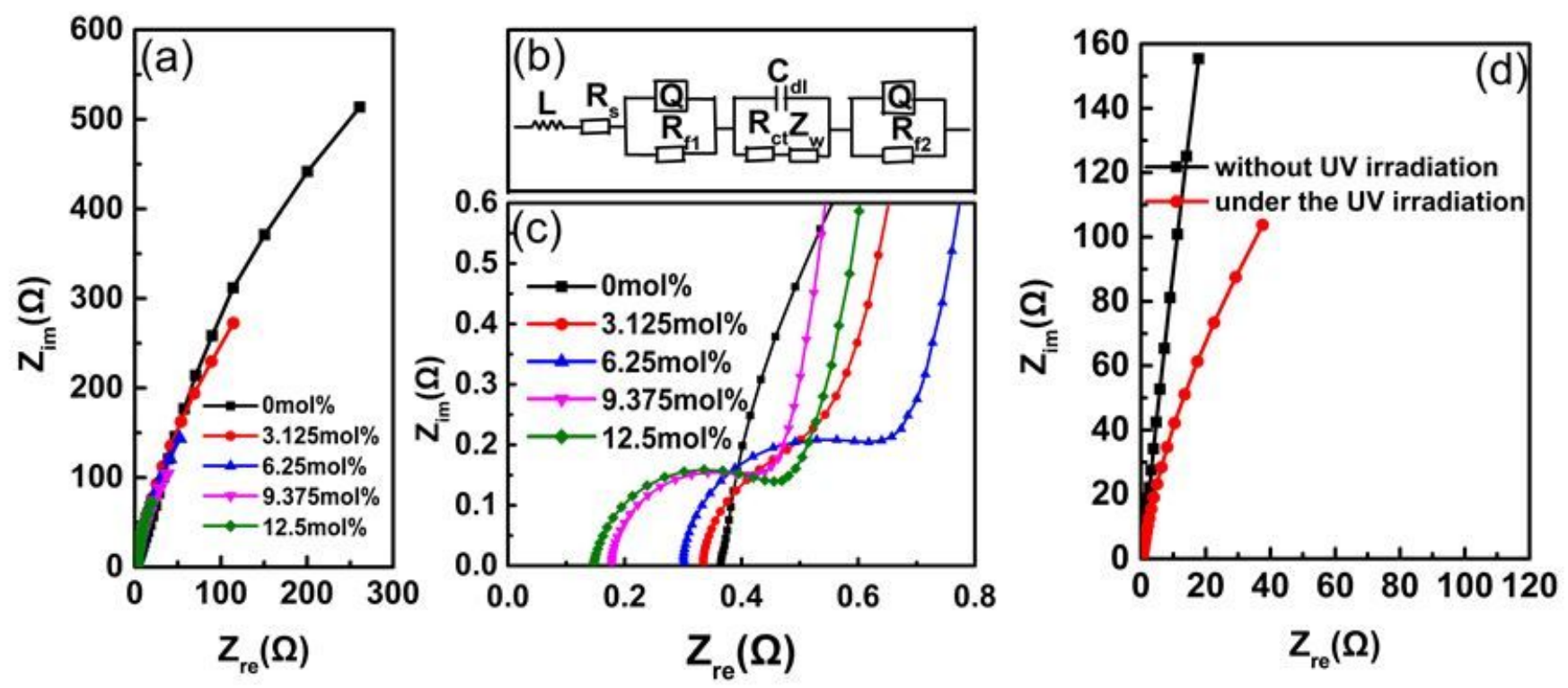

Figure 9

(a) Nyquist plots of the RuxZn1-xO/Ti electrodes; (b) the electrical equivalent circuit for the fitting of the impedance spectra; (c) the enlarged view of the high frequency region of the Nyquist plots; (d) the Nyquist plots with and without UV irradiation. 

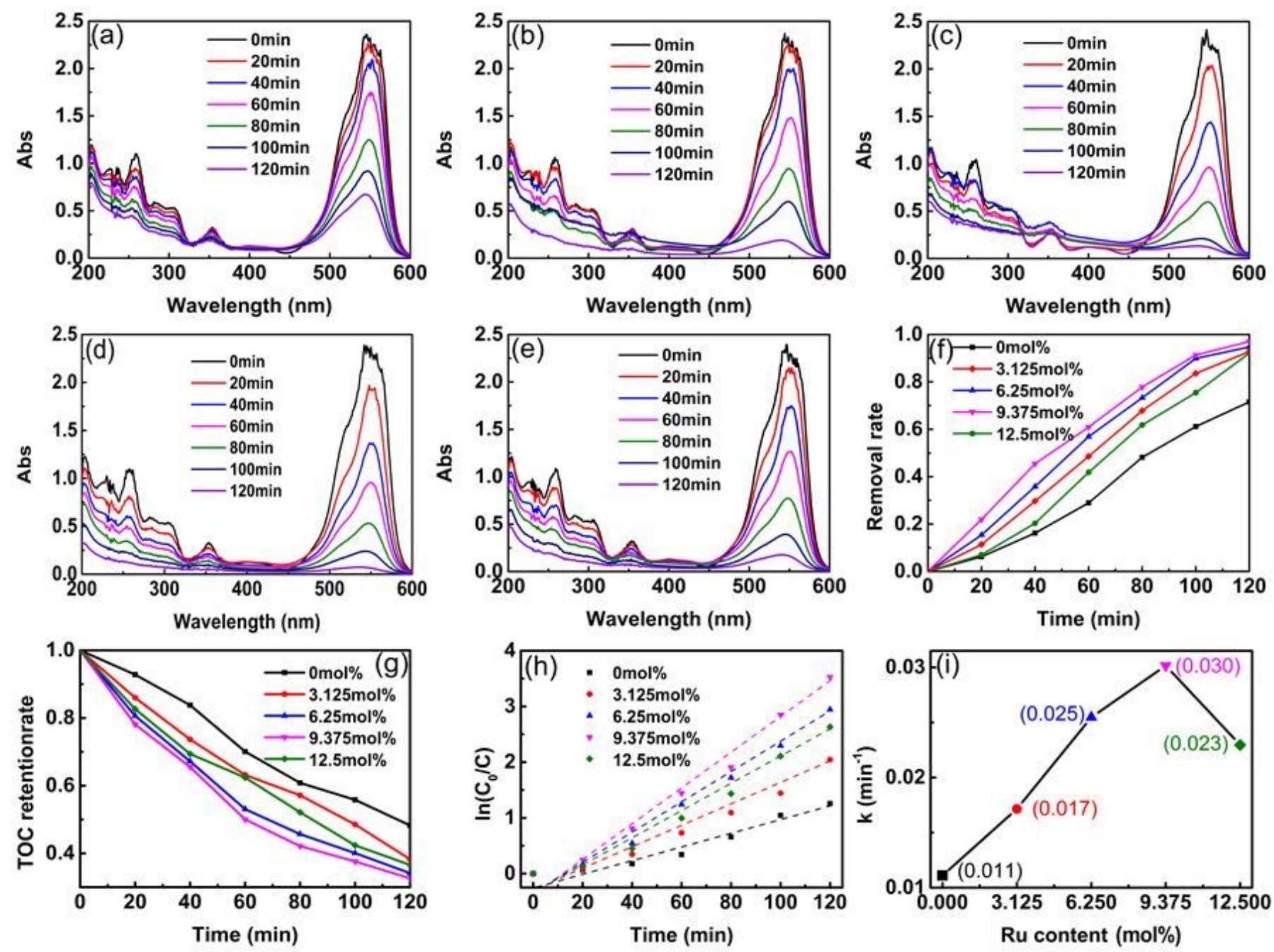

Figure 10

UV-vis absorption spectra of RuxZn1-xO/Ti electrodes under PEC degradation with different intervals (a) Omol\%; (b) $3.125 \mathrm{~mol} \%$; (c) $6.25 \mathrm{~mol} \%$; (d) $9.375 \mathrm{~mol} \%$; (e) $12.5 \mathrm{~mol} \%$; along with (f) removal ratio of RhB; (g) removal ratio of TOC; (h) degradation kinetics; (i) the reaction rate constant. 

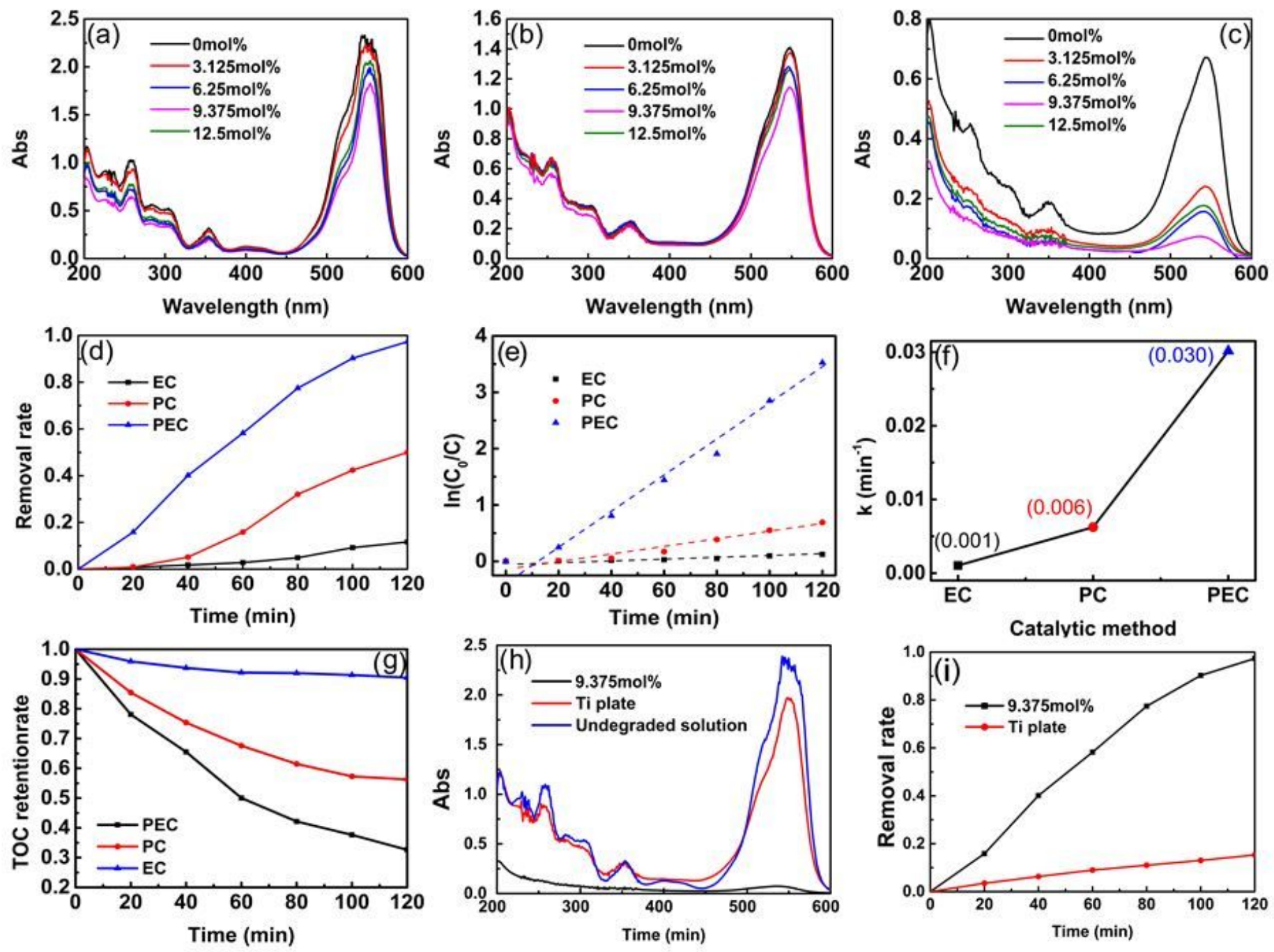

Figure 11

UV-visible absorption spectra of RuxZn1-xO/Ti electrodes containing of $9.375 \mathrm{~mol} \%$ Ru with different catalytic methods (a) EC; (b) PC; (c) PEC; (d) removal rates of PEC, PC and EC; (e) degradation kinetics; (f) reaction rate constant; (g) TOC removal rates of PEC, PC and EC; (h) Comparison UV-visible absorption specta after 120 min degradation; (i) removal rates of electrodes containing $9.375 \mathrm{~mol} \%$ Ru and Ti plates. 


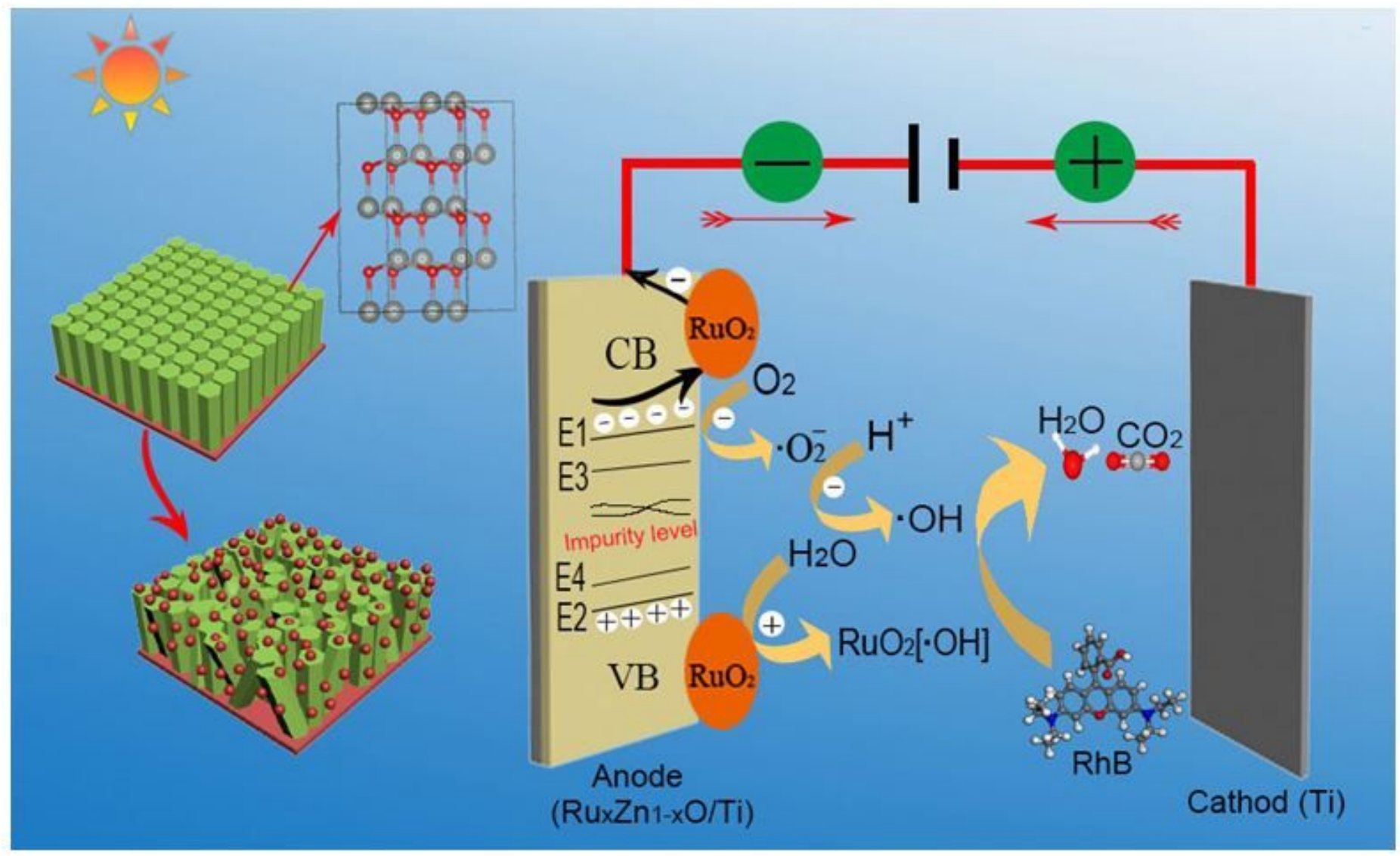

Figure 12

Schematic microstructure model and PEC mechanism of RuxZn1-xO/Ti electrodes. 